\title{
Avaliação Económica de programas de saúde Essencial sobre conceitos, metodologia, dificuldades e oportunidades
}

Óscar Lourenço, ${ }^{*}$ Vladimiro Silva**

\section{RESUMO}

Neste artigo tentar-se-á proporcionar uma visão geral sobre os principais métodos utilizados na avaliação económica de tecnologias de saúde e o modo como estes contribuem para que a decisão sobre a respectiva utilização possa ser baseada em evidência científica credível e obtida de forma sistematizada e transparente.

A literatura identifica quatro tipos de avaliação económica de programas de saúde: análise de custos, análise de custo-efectividade, análise de custo-utilidade e análise de custo-benefício.

As análises de custo-efectividade (que medem as consequências em unidades naturais) e de custo-utilidade (em que as consequências são medidas em QALYs - Quality-Adjusted Life Years) são as mais frequentemente utilizadas em processos de Avaliação de Tecnologias de Saúde.

Nas situações em que não existam dados económicos ou de efectividade a nível individual provenientes de ensaios clínicos de qualidade que permitam a respectiva utilização em estudos de avaliação económica é necessário recorrer a modelos matemáticos, de modo a combinar e sintetizar toda a evidência disponível. A modelação permite também extrapolar de consequências intermédias para consequências finais ou para um horizonte temporal apropriado, incorporar elementos de incerteza e ainda extrapolar consequências dos programas de saúde (efectividade/QALYs) para o contexto real em que estes vão ser implementados.

A incerteza inevitavelmente associada a todos os tipos de avaliação económica deve ser medida e incorporada nas análises, existindo técnicas que permitem atingir este objectivo e dar ao decisor político uma medida da robustez das conclusões das avaliações económicas.

O indicador mais frequentemente adoptado para relacionar custos e consequências em estudos de avaliação económica é o Rácio Incremental Custo-Efectividade (Incremental Cost-Effectiveness Ratio - ICER) e o seu cálculo e utilização na elaboração de recomendações finais de estudos de avaliação económica será explicado no último capítulo deste texto.

\section{INTRODUÇÃO}

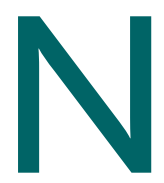
um mundo ideal as palavras «Economia»e «Saúde» só muito raramente seriam encontradas na mesma frase. De facto, sendo muitas vezes referida como um valor para o qual não é possível atribuir um preço, teoricamente a Saúde deveria beneficiar de recursos ilimitados, sem qualquer tipo de restrições às necessidades que inevitavelmente decorrem da prestação dos serviços.

No entanto, como todos muito bem sabemos, infelizmente os recursos (pessoas, tempo, instalações, equi-

\footnotetext{
*Faculdade de Economia da Universidade de Coimbra

**AIBILI - Unidade de Avaliação de Tecnologias de Saúde (ATS) e Ferticentro -

Centro de Estudos de Fertilidade, Coimbra.
}

pamento e conhecimento) são escassos e no sector da Saúde comportam-se frequentemente como um cobertor demasiado curto: quando se tapa a cabeça destapam-se os pés e quando se tapam os pés fica a cabeça exposta, ou seja, qualquer utilização menos eficiente de um determinado bem ou serviço fará com que outro não possa ser prestado - o custo do sacrifício da utilização alternativa dos recursos alocados a bens ou serviços de saúde (custo de oportunidade) estará sempre presente, qualquer que seja o contexto em análise.

Na administração e na prestação de serviços de saúde é e será sempre necessário fazer escolhas, tomar decisões, seleccionar um serviço em detrimento de outro, prescrever um medicamento e não outro(s), comprar 
um determinado equipamento de entre os vários que existem no mercado, etc. Frequentemente no sector da Saúde os recursos são afectos com base em regras $a d$ - hoc («fazemos como fizemos na última vez»), palpites, intuição ou outros motivos para os quais não existe uma fundamentação sólida. Porém, num mundo tão complexo como o actual, com tantas utilizações alternativas possíveis, é pouco provável que a ausência de um conjunto de procedimentos sistematizados, organizados e tecnicamente bem sustentados possa permitir a utilização mais eficiente dos recursos disponíveis. Sem regras para decidir e sem uma análise cuidadosa são omitidas alternativas, não são identificados todos os custos nem todas as consequências e não existem igualmente métodos explícitos para tratar a incerteza, o que inevitavelmente conduz a uma afectação ineficiente dos recursos, com o seu consequente desperdício.

É pois necessário utilizar métodos que permitam medir e avaliar com a maior precisão possível os custos de oportunidade dos bens e serviços de saúde, pois são estes que verdadeiramente interessam à sociedade e podem ser comparados com os benefícios obtidos. Só assim será possível assegurar que a sociedade obtém o máximo benefício dos recursos que pode disponibilizar aos serviços de saúde e que estes possam ser utilizados de uma forma racional, efectiva e eficiente.

E é aqui que surge a Economia da Saúde, uma disciplina que integra as teorias económicas, sociais, clínicas e epidemiológicas e que procura estudar os mecanismos e factores que determinam e condicionam a produção, distribuição, consumo e financiamento dos bens e serviços de saúde.

\section{A AVALIAÇÃO ECONÓMICA DE TECNOLOGIAS DE SAÚDE}

Nos últimos anos assistiu-se nos países desenvolvidos a um crescimento exponencial na introdução e consumo de tecnologias de saúde, tendo surgido inúmeros novos medicamentos, meios complementares de diagnóstico, equipamentos cirúrgicos, etc. Esta vaga de inovação permitiu que governos, prestadores de cuidados de saúde e doentes pudessem beneficiar de serviços de saúde melhorados, bem como dos ganhos em saúde que naturalmente decorrem da respectiva utilização.

Por outro lado, a rápida difusão das novas tecnolo- gias coloca aos governos um conjunto de desafios sem precedente, que é o de proporcionar à população cuidados de saúde modernos, inovadores, seguros, de elevada qualidade e que vão ao encontro das necessidades existentes, ao mesmo tempo que tentam respeitar os eternos constrangimentos orçamentais dos sistemas de saúde e se procuram respeitar princípios como a equidade, acesso universal e direito de escolha pelos utentes.

Aos governos é exigida uma gestão estratégica e eficaz dos escassos recursos disponíveis e, no caso da saúde, isso significa concentrar os recursos nos bens e serviços que sejam susceptíveis de originar melhores resultados em saúde, isto é, em cuidados que sejam efectivos, economicamente comportáveis, seguros e focados no doente. É também necessário que os governos tenham capacidade de proporcionar um acesso adequado à inovação, numa medida tão próxima quanto possível da das necessidades da população.

Nos últimos anos têm surgido em vários países agências governamentais cujo objectivo é a identificação de inovações que proporcionem o melhor valor possível, o denominado value for money. A mais conhecida destas é o National Institute for Clinical Excellence (NICE), no Reino Unido, que foi também a primeira instituição governamental cuja actividade se centrava em procurar, com base num processo de revisão sistemático e baseado na evidência, promover o acesso aos cuidados de saúde mais custo-efectivos. Embora nem sempre isentos de controvérsia, os relatórios do NICE tiveram e têm o inegável mérito de servirem de padrão a outros países e de promoverem uma cultura de avaliação sistemática e baseada na evidência relativamente às tecnologias de saúde.

Este tipo de instituições utiliza metodologias de Avaliação de Tecnologias de Saúde (ATS) para valorizar os custos e benefícios relativos de cada tecnologia. A evidência obtida é utilizada como suporte para o processo político de decisão, nomeadamente para aspectos relacionados com financiamento, comparticipação e definição de preços. Por outras palavras, a informação obtida através do processo de ATS é fundamental para a definição de prioridades dos sistemas de saúde e para um processo de alocação de recursos sistemático e transparente.

Segundo a definição da International Society of 
Technology Assessment in Health Care, a ATS consiste na avaliação sistemática das propriedades, efeitos e/ou outros impactos das tecnologias de saúde (não só medicamentos, dispositivos e equipamentos médicos, mas também todas as intervenções que possam estar associadas à prevenção, diagnóstico, terapia e acompanhamento da doença), o que, de um modo mais detalhado, se pode traduzir na avaliação de uma determinada intervenção através da produção, síntese e/ou revisão sistemática da evidência científica e não científica disponível sobre a segurança, eficácia, custo e custo-efectividade de produtos ou serviços de saúde. A ATS preocupa-se também com as implicações sociais, organizacionais, legais e éticas que decorrem da utilização dos produtos ou serviços em análise, como por exemplo os impactos macroeconómicos alargados no orçamento do serviço nacional de saúde, a decisão de alocação de recursos entre diferentes programas de saúde ou aspectos como a regulação e alterações políticas associadas à adopção da inovação (investimento, transferência de tecnologia, emprego). Além de identificar e promover a utilização das tecnologias de saúde de maior valor, uma ATS efectiva pode reduzir ou eliminar o uso de intervenções que não sejam suficientemente seguras e efectivas ou que tenham uma relação custo-benefício desfavorável, para além de identificar tecnologias subutilizadas.

Deste modo, uma das componentes vitais da ATS é a utilização de processos de avaliação económica documentados e validados internacionalmente. Neste artigo tentaremos proporcionar uma visão geral sobre os principais métodos utilizados na avaliação económica de tecnologias de saúde e o modo como estes contribuem para que a decisão política sobre a respectiva utilização possa ser baseada em informação sólida, baseada em evidência científica credível e obtida de um modo sistematizado e transparente.

Procuraremos também referir aspectos metodológicos concretos, como a determinação das consequências em estudos de custo-utilidade ou o cálculo do rácio incremental de custo-efectividade e falaremos da importância da modelação nos estudos de avaliação económica actuais.

Os estudos de avaliação económica não são uma fórmula milagrosa que permita aos administradores dos serviços e sistemas de saúde saber qual a decisão mais acertada em cada momento, mas são seguramente uma boa oportunidade para organizar informação estruturada sobre programas de saúde, e fornecer mais um input valioso para que todo o processo de tomada de decisão tenha a qualidade desejada.

\section{TÉCNICAS DE AVALIAÇÃO ECONÓMICA}

No sector da Saúde é frequente encontrarem-se situações que podem ser resolvidas por mais que uma forma. Por exemplo, podem existir dois antibióticos diferentes para o tratamento da mesma infecção ou duas técnicas cirúrgicas alternativas para resolver um determinado problema, podendo ainda a comparação ser feita contra a hipótese de simplesmente não se actuar.

Os administradores de sistemas e serviços de saúde são também frequentemente confrontados com questões sobre quem deve fazer o quê e a quem, com que recursos e com que relação com outros serviços de saúde - a adopção de planos de saúde preventiva, programas de rastreio de determinadas doenças, aquisição de novos equipamentos, gestão de recursos humanos entre diferentes serviços de saúde ou a inclusão de medicamentos em formulários de prescrição são alguns exemplos de questões que surgem diariamente e para as quais não há uma resposta óbvia. Normalmente estes problemas são resolvidos com base em estimativas pessoais sobre o mérito relativo de cada alternativa em análise - poder-se-á escolher, por exemplo, o antibiótico mais efectivo, ou então o critério a adoptar poderá ser o preço, seleccionando-se nesse caso o mais barato. Contudo, na maior parte das situações, e na ausência de procedimentos sistematizados, estas decisões são baseadas em informação pouco consistente e dificilmente reprodutível.

Avaliação económica é a designação genérica de um conjunto de técnicas utilizadas para identificar, medir e valorizar custos e resultados das intervenções de saúde, sendo definida como «a análise comparativa de atitudes alternativas tendo em conta os respectivos custos e consequências». ${ }^{1}$

A avaliação económica preocupa-se em identificar a relação entre custos e consequências nas várias opções disponíveis, pois é com base nesta informação que se podem tomar as decisões: poucos estariam dispostos a pagar por uma encomenda cujo conteúdo desconhecessem e, do mesmo modo, poucos estariam dispostos 
a aceitar uma embalagem que, apesar de ter um conteúdo desejado e bem conhecido, tivesse um preço desconhecido. ${ }^{1}$ Em ambos os casos, é da ligação entre custos e consequências que se retiram os elementos que sustentam a decisão de adquirir ou não o bem em causa.

A avaliação económica pode ser usada como fonte de informação para o processo de tomada de decisão e permite ajudar a determinar que tipo de serviços se devem prestar, onde, como e a que nível deve ocorrer essa prestação. Os estudos de avaliação económica preocupam-se em responder essencialmente a dois tipos de questões:

Vale a pena investir neste bem ou serviço de saúde tendo em conta as outras utilizações que os mesmos recursos poderiam ter se fossem aplicados noutras actividades?

Consideramos aceitável que os recursos de cuidados de saúde necessários para que este bem ou serviço de saúde possa ser prestado sejam gastos desta forma e não de um modo alternativo?

É comum classificar os estudos de avaliação económica de programas de saúde em quatro tipos, que apresentam diferenças apenas na forma de medição das consequências, uma vez que todos envolvem a consideração de custos:

- Análise de custos;

- Análise de custo-efectividade;
- Análise de custo-utilidade;

- Análise de custo-benefício.

No Quadro I pode observar-se uma comparação resumida da forma como os diferentes estudos de avaliação económica tratam custos e consequências.

Se se demonstrar que as consequências associadas a todas as alternativas em análise são idênticas nas características relevantes para o estudo, admite-se a realização apenas de uma análise de custos, por vezes também designada de análise de minimização de custos. A simples análise dos custos de um determinado serviço de saúde não é considerada um estudo de avaliação económica completo. Uma avaliação económica completa pressupõe a comparação de duas ou mais alternativas em relação aos respectivos custos e consequências. Só os estudos de custo-efectividade, custo-utilidade e custo-benefício reúnem condições para poderem ser considerados como avaliações económicas completas. Briggs e O'Brien ${ }^{2}$ referem que, devido à incerteza associada às determinações de custos e consequências, são extremamente raras as situações em que duas intervenções podem ser consideradas como tendo consequências equivalentes (o que só pode ser afirmado com base em opiniões profissionais ou estudos prévios), pelo que a opção por este tipo de análise deverá ser sempre bem justificada e encarada com a devida prudência.

Nos casos em que há diferenças nas consequências

QUADRO I. Medidas de custos e consequências em estudos de avaliação económica
\begin{tabular}{l|l|l|l|}
\multicolumn{1}{c|}{ Tipo de estudo } & $\begin{array}{l}\text { Medida } \\
\text { dos custos }\end{array}$ & Identificação das consequências & \multicolumn{1}{c}{ Medida das consequências } \\
\hline Análise de custos (AC) & $\begin{array}{l}\text { Unidades } \\
\text { monetárias }\end{array}$ & $\begin{array}{l}\text { As consequências são comuns às } \\
\text { alternativas consideradas }\end{array}$ & $\begin{array}{l}\text { As consequências são comuns às alternativas } \\
\text { consideradas }\end{array}$ \\
\hline $\begin{array}{l}\text { Análise de } \\
\text { custo-efectividade } \\
\text { (ACE) }\end{array}$ & $\begin{array}{l}\text { Unidades } \\
\text { monetárias }\end{array}$ & $\begin{array}{l}\text { Um único efeito, comum a todas } \\
\text { as alternativas, mas atingido em } \\
\text { graus diferentes }\end{array}$ & $\begin{array}{l}\text { Unidades naturais (anos de vida ganhos, número } \\
\text { de mortes evitadas, partos, unidades de redução } \\
\text { da pressão arterial, diminuição da concentração } \\
\text { de colesterol LDL, etc.) }\end{array}$ \\
\hline $\begin{array}{l}\text { Análise de } \\
\text { custo-utilidade (ACU) }\end{array}$ & $\begin{array}{l}\text { Unidades } \\
\text { monetárias }\end{array}$ & $\begin{array}{l}\text { Um ou mais efeitos, não } \\
\text { necessariamente comuns } \\
\text { às várias alternativas }\end{array}$ & $\begin{array}{l}\text { QALYs (Quality Adjusted Life Years - anos de vida } \\
\text { ganhos ponderados pela qualidade de vida } \\
\text { relacionada com a saúde) }\end{array}$ \\
\hline $\begin{array}{l}\text { Análise de } \\
\text { custo-benefício (ACB) }\end{array}$ & $\begin{array}{l}\text { Unidades } \\
\text { monetárias }\end{array}$ & $\begin{array}{l}\text { Um ou mais efeitos, não } \\
\text { necessariamente comuns às } \\
\text { várias alternativas }\end{array}$ & Unidades monetárias \\
\hline
\end{tabular}


ou no grau em que estas são atingidas, deve ser efectuada uma análise de custo-efectividade, sendo no entanto preferível a opção por estudos de custo-utilidade ou custo-benefício, de modo a tornar comparáveis os resultados de estudos relativos a diferentes patologias.

A análise de custo-benefício baseia-se na teoria económica do bem-estar e difere dos outros métodos de avaliação económica por valorizar custos e consequências em termos monetários, o que permite comparações também com investimentos noutros sectores que não apenas o da saúde. Contudo, na prática a realização deste tipo de análise envolve dificuldades de medição bastante complexas (como a valorização contingente), pelo que a sua utilização é menos comum. Os resultados dos estudos de custo-benefício são apresentados sob a forma de rácio entre custos e benefícios ou então como uma soma (cujo resultado pode ser negativo) que represente o benefício líquido de uma alternativa sobre a outra.

Os estudos de custo-efectividade e custo-utilidade assumem implicitamente que uma das alternativas em análise será sempre realizada, independentemente do seu benefício líquido - ou seja, considera-se sempre que quer a efectividade, quer a utilidade medidas são objectivos que vale a pena atingir e o que está em causa é apenas a melhor forma de o concretizar. Isto não acontece com a análise custo-benefício, que proporciona informação sobre o benefício absoluto do programa de saúde em causa - e esse benefício é que será alvo da decisão de o realizar ou não.

Estas técnicas não são mutuamente exclusivas e um estudo que apresente, por exemplo, resultados baseados simultaneamente nos métodos de análise custo-efectividade e custo-utilidade constituirá uma melhor base de decisão que outro que contemple apenas uma técnica de avaliação económica.

\section{IDENTIFICAÇÃO E MEDIÇÃO DOS CUSTOS NAS AVALIAÇÕES ECONÓMICAS}

A análise comparativa dos custos de tratamentos alternativos é comum a todas as formas de avaliação económica, pelo que é fundamental que estes sejam identificados, medidos e valorizados correctamente.

No sector da Saúde as principais categorias de custos são:

- Custos que resultam da utilização de recursos pelos serviços de saúde;

- Custos que resultam da utilização de recursos pelos doentes e respectivas famílias;

- Custos que surgem noutros sectores de actividade;

- Variações na produtividade decorrentes da realização dos serviços.

Ou seja, de um modo mais sistematizado, existem:

- Custos directos - custos directamente associados à prestação do serviço de saúde. Podem ser fixos (ocorrem quer o doente seja tratado ou não - por exemplo, custos de capital, electricidade, limpeza, etc.) ou variáveis (apenas ocorrem quando o serviço é prestado - por exemplo, reagentes e materiais descartáveis, análises clínicas, medicamentos, etc.). Também existem custos directos não médicos, que ocorrem noutros sectores que não o da Saúde (por exemplo, despesas de deslocação dos doentes até aos serviços de saúde, custos do apoio social a crianças ou idosos, pensões de invalidez, etc.);

- Custos indirectos - estão associados à diminuição de produtividade que a doença ou tratamento provoca no doente e respectiva família (tempo de ausência do trabalho, acréscimo de tarefas domésticas, tempo despendido em consultas médicas, tempo de lazer perdido, etc.). No entanto, este tipo de custos é difícil de calcular, pois tendem a favorecer as intervenções em que os doentes estão empregados (uma forma de resolver este problema é a atribuição de um valor às actividades não pagas). Os únicos custos indirectos que é possível determinar de uma forma consistente são o tempo de trabalho perdido por baixa médica, a reforma antecipada e a diminuição da produtividade no trabalho. O impacto dos custos indirectos é bastante variável entre doenças e tratamentos e normalmente é significativo nos estudos de avaliação económica. Contudo, devido à dificuldade técnica do seu cálculo é pouco frequente encontrarem-se estudos que os considerem - embora fosse desejável que todos os estudos o fizessem;

- Custos intangíveis - são extremamente difíceis ou mesmo impossíveis de determinar, embora ocorram e por isso seja desejável que sejam considerados sempre que possível. Incluem aspectos como a ansiedade, dor ou sofrimento com uma doença. Como exemplo de um serviço que tem simultaneamente custos directos, indirectos e intangíveis podem refe- 


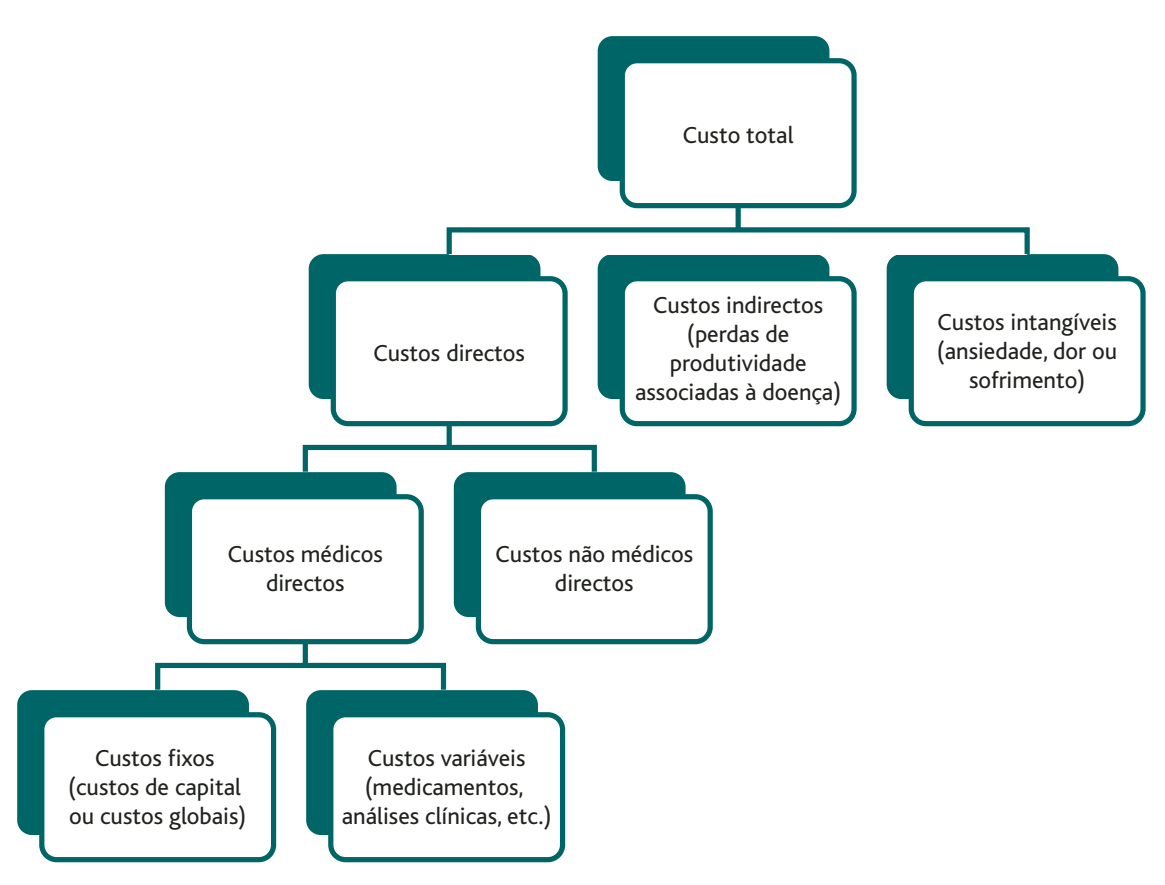

Figura 1. Tipos de custos numa avaliação económica.

rir-se os programas de rastreio da hipercolesterolemia em farmácias comunitárias - neste caso os custos intangíveis são os que se relacionam com a ansiedade inerente ao processo de rastreio e ao receio de conhecer o respectivo resultado.

Na Figura 1 pode observar-se uma representação esquemática dos tipos de custos existentes nos serviços de saúde, embora existam autores de referência ${ }^{1}$ que defendem que estas designações devem ser abandonadas, pois são susceptíveis de causar confusão.

Na determinação dos custos de serviços de saúde são necessários alguns cuidados, nomeadamente:

- A perspectiva dos custos. Existem situações em que um determinado item pode ser um custo apenas numa perspectiva, que não é necessariamente a que interessa à análise económica em causa. Por exemplo, as despesas de deslocação dos doentes até aos serviços de saúde só devem ser consideradas como custo quando se está a fazer um estudo na perspectiva dos doentes, uma vez que noutras perspectivas (por exemplo, dos hospitais ou do serviço nacional de saúde) este é um custo que não é considerado na avaliação económica dos serviços disponibilizados.
Quando não é clara a perspectiva a adoptar num determinado estudo, opta-se geralmente por considerar o ponto de vista da sociedade, que é o de maior abrangência e de interesse mais relevante;

- A existência de custos comuns aos serviços/procedimentos em análise. Por vezes, quando se comparam serviços ou procedimentos que apresentam custos comuns, é frequente eliminarem-se esses custos da análise, o que permite consideráveis economias de tempo e facilita os estudos. Este procedimento é correcto, mas é necessário ter alguma prudência quando se utilizam estas análises para comparações com outros serviços/procedimentos que eventualmente poderão não partilhar os custos comuns (que neste caso deverão passar a ser considerados);

- A identificação dos verdadeiros custos dos serviços/procedimentos em avaliação. Num estudo de avaliação económica devem ser considerados custos de oportunidade, ou seja, custos que traduzam o valor social da melhor utilização alternativa dos recursos sacrificados. Num mercado perfeitamente concorrencial, os preços de mercado estariam directamente associados aos custos de oportunidade. No 
entanto, no caso específico da saúde, que é um mercado imperfeito (uma vez que os preços praticados nem sempre traduzem directamente o custo da prestação dos serviços, mas dependem de factores como a intervenção governamental, marketing, etc.) são necessários cuidados adicionais quando se utilizam os preços dos serviços como forma de chegar aos respectivos custos de oportunidade. Também os preços constantes das tabelas do SNS de preços de grupos de diagnóstico homogéneo (GDHs) e de meios complementares de diagnóstico e terapêutica (MCDTs) podem ser indutores de erro, uma vez que se trata de valores criados com o objectivo de adequar a alocação de recursos a determinados serviços (contratualização, facturação a subsistemas ou seguradoras, etc.), visando sobretudo financiar a produção hospitalar e não identificar e quantificar rigorosamente o respectivo custo. Ou seja, num estudo económico que envolva a análise dos custos de um determinado serviço ou procedimento, são preferíveis os dados da contabilidade analítica da instituição em causa (embora também exista alguma variabilidade, agravada pelas diferenças do regime de gestão, por exemplo entre hospitais EPE e do sector público administrativo) às referidas tabelas do SNS;

- A utilização de custos médios ou custos marginais. Um dos principais problemas que surgem nos trabalhos de análise de custos tem a ver com a decisão entre utilizar custos médios (que incluem custos fixos, como por exemplo os que se relacionam com infra-estruturas, limpeza, recursos humanos administrativos, etc.) ou custos marginais (situação em que se considera apenas o custo de prestar mais uma unidade de serviço/procedimento, mas se ignoram os custos fixos). Por exemplo, se o processo de análise de decisão faz com que se chegue a uma situação em que a prestação adicional de um serviço requer a expansão de infra-estruturas não se podem considerar apenas os custos marginais tradicionalmente avaliados, sob pena de se subestimarem significativamente os custos sociais da intervenção em causa.

Embora grande parte dos aspectos associados às técnicas de custeio utilizadas em Economia da Saúde dependa de factores relacionados com o contexto e disponibilidade de dados, há outros parâmetros que é possível uniformizar e que se relacionam as principais di- ficuldades que surgem quando se calculam os custos de qualquer procedimento:

- O tratamento dos custos «overhead» (alocação de custos globais e partilhados a processos individuais);

- O factor tempo (técnicas de aplicação de taxas de desconto ou actualização de despesas de capital - no sector da Saúde é comum utilizar-se uma taxa de desconto entre $4 \%$ e $6 \%$, mais frequentemente $5 \%$ ). Acima de tudo, o principal aspecto a ter em consideração quando se faz uma análise de custos é que, para os economistas, os custos dizem respeito ao sacrifício que decorre do consumo de um recurso por um determinado serviço ou procedimento.

Deste modo, devemos ter alguma prudência, de modo a que o estudo não se limite a analisar despesas, mas também tenha em consideração todos os restantes aspectos referidos neste capítulo, cuja tradução nos preços de mercado nem sempre ocorre de um modo adequado ou fácil de identificar.

\section{IDENTIFICAÇÃO DAS CONSEQUÊNCIAS NAS ANÁLISES CUSTO-EFECTIVIDADE E CUSTO-UTILIDADE}

\section{Análise das consequências nas ACE}

A análise de custo-efectividade é uma forma de avaliação económica completa que traduz as consequências das diversas alternativas em unidades naturais adequadas ao problema em análise - por exemplo, no caso da hipertensão é comum utilizarem-se unidades de pressão arterial, casos correctamente diagnosticados ou anos de vida ganhos. Assim, ao contrário do que sucede no caso da análise de custo-benefício, não é feita qualquer tentativa de atribuir um valor monetário à medida da efectividade do tratamento.

A disponibilidade de dados de boa qualidade relativamente à efectividade dos serviços ou tratamentos em avaliação é crucial para a análise de custo-efectividade. De facto, as críticas a este tipo de estudos têm normalmente mais a ver com a qualidade dos dados de efectividade do que propriamente com a parte económica construída a partir destes.

A principal fonte de dados de efectividade é a literatura médica existente, cuja utilização em estudos de avaliação económica deve ser sempre feita depois de se avaliar a respectiva qualidade, relevância e grau de completitude. ${ }^{1}$ De um modo geral, os economistas uti- 


\begin{tabular}{|l|l|l|}
\hline \multicolumn{2}{|c|}{$\begin{array}{l}\text { QUADRO II. Relação entre níveis de evidência e grau de } \\
\text { recomendação: Adaptado de Drummond et al. }{ }^{1}\end{array}$} \\
$\begin{array}{l}\text { Nível de } \\
\text { evidência }\end{array}$ & $\begin{array}{l}\text { Trau de } \\
\text { Nível I }\end{array}$ & $\begin{array}{l}\text { Estudos aleatorizados e } \\
\text { controlados de grande escala } \\
\text { com resultados claros } \\
\text { (baixo risco de erro) }\end{array}$ \\
\hline Nível II & $\begin{array}{l}\text { Estudos aleatorizados e } \\
\text { controlados de pequena escala } \\
\text { e resultados incertos (risco de } \\
\text { erro moderado ou elevado) }\end{array}$ & Grau A \\
\hline Nível III & $\begin{array}{l}\text { Estudos de caso-controlo } \\
\text { contemporâneos e não } \\
\text { aleatorizados }\end{array}$ & Grau C \\
\hline Nível IV & $\begin{array}{l}\text { Estudos de caso-controlo } \\
\text { retrospectivos e não } \\
\text { aleatorizados }\end{array}$ & Grau D \\
\hline Nível V & $\begin{array}{l}\text { Séries de casos, sem controlo } \\
\text { Grau E }\end{array}$ \\
\hline
\end{tabular}

lizam o mesmo tipo de critérios que os epidemiologistas quando se trata de aferir a qualidade dos estudos disponíveis, existindo níveis de recomendação relacionados com a robustez dos estudos e da evidência proporcionada (Quadro II), sendo que as revisões sistemáticas e meta-análises de ensaios clínicos controlados e aleatorizados, bem delineados e executados são consideradas como ideais para a realização de estudos de custo-efectividade. Embora fosse de facto desejável que todos os estudos económicos fossem realizados com base em estudos aleatorizados, há situações em que isso não é possível, como por exemplo a probabilidade de ocorrência de um efeito secundário raro, que provavelmente só poderá ser obtida a partir de estudos observacionais e não controlados ou casos em que a falta de informação apropriada obriga a recorrer a um painel de peritos (opção menos desejável do que qualquer uma das referidas na Quadro II ).

Na avaliação da relevância dos resultados publicados na literatura, o primeiro aspecto a ter em consideração é o grau de proximidade entre a situação sobre a qual incide o estudo de avaliação económica e os trabalhos disponíveis. Neste caso, os aspectos mais importantes a avaliar são a dimensão da amostra e o grau de espe- cialização das equipas médicas e técnicas envolvidas.

Por vezes, a avaliação da qualidade de um estudo colide com a da relevância - em algumas situações os estudos aleatorizados e controlados são conduzidos em contextos particulares e que não são exactamente os que mais interessam à avaliação económica: por exemplo, pode existir selecção de doentes, o ensaio pode ser duplamente cego, a comparação pode ser feita contra placebo e não contra outro princípio activo, o protocolo do ensaio pode exigir a realização de outros testes ou procedimentos ou podem existir ensaios em que os doentes são monitorizados e acompanhados de perto como forma de garantir adesão à terapêutica. Todas estas condições podem fazer sentido no contexto dos objectivos do ensaio clínico (avaliação da eficácia da terapia), mas não proporcionam muita informação relativamente ao modo como a aplicação desta ocorre num contexto clínico real (ou seja, não contribuem da mesma forma para a determinação da efectividade).

Idealmente os estudos de avaliação económica deveriam ser baseados em dados de efectividade e não de eficácia. No entanto, nem sempre estes estão disponíveis, pelo menos sob a forma de ensaios aleatorizados e controlados, o que coloca algumas dificuldades aos analistas económicos, que para o contornar utilizam habitualmente algumas estratégias:

- Realização da análise económica em simultâneo com o ensaio clínico, o que levanta vários problemas práticos e metodológicos que não é objectivo deste artigo discutir, mas que se relacionam essencialmente com a adequação dos ensaios à análise económica e às dificuldades adicionais de recolha de dados; ${ }^{1}$

- Introdução de ajustamentos a ensaios já publicados na literatura médica, o que também não é um processo fácil devido ao facto de existirem custos que decorrem da natureza do próprio ensaio clínico (veja-se, por exemplo, o caso de ensaios clínicos de medicamentos para o tratamento da úlcera péptica em que os doentes são mensalmente sujeitos a endoscopias digestivas: naturalmente que o custo destes procedimentos deve ser excluído da análise económica, embora por outro lado também devam ser considerados os casos não diagnosticados na prática clínica quotidiana), à variabilidade na prática clínica ou à existência de diferentes convenções entre locais de tratamento distintos. 
O terceiro critério para avaliação da efectividade utilizável em estudos de avaliação económica é o grau de completitude (comprehensiveness) - ou seja, em que medida é que os dados clínicos utilizados na avaliação económica são representativos da literatura médica no seu todo. Este aspecto foi, pela primeira vez, levantado por Freemantle e Maynard, ${ }^{3}$ que defenderam que o uso de ensaios clínicos seleccionados na avaliação económica de anti-depressivos fez com que estes fármacos apresentassem avaliações de custo-efectividade mais favoráveis que as que ocorriam quando eram considerados todos os dados disponíveis. Este aspecto pode ser resolvido através da realização de revisões sistemáticas dos dados de efectividade, utilizando critérios metodológicos claros e que incluem a descrição das técnicas de pesquisa da literatura, critérios de inclusão e exclusão dos trabalhos encontrados, selecção de objectivos clínicos pretendidos, registo de características individuais dos estudos (por exemplo, características dos doentes envolvidos), detalhes terapêuticos, testes de homogeneidade estatística, análise de sensibilidade, etc.

Nas situações em que não existe evidência clínica de boa qualidade, a análise de custo-efectividade pode prosseguir com base em pressupostos relativos à informação em falta, que terão que ser validados posteriormente por um processo de análise de sensibilidade dos resultados económicos obtidos com cada pressuposto assumido. Assim, se a análise de sensibilidade mostrar que a adopção de diferentes pressupostos não é susceptível de afectar o resultado do estudo, não é necessário reunir evidências mais precisas sobre os dados em falta. Este método poderá permitir evitar que os estudos de custo-efectividade fiquem dependentes de demorados e custosos processos acrescidos de recolha de dados.

\section{Identificação das consequências nas ACU}

As análises de custo-efectividade são a técnica de avaliação económica adequada quando as consequências das tecnologias de saúde em avaliação podem ser medidas numa escala de medida comum, geralmente denominada como unidades naturais. Este é um aspecto limitador da aplicação desta classe de análises pois com frequência as tecnologias de saúde apresentam consequências que dificilmente podem ser medidas numa escala comum, para além de terem múltiplos efeitos que também interessa considerar. Este aspecto limita igualmente a aplicação da ACE como técnica de avaliação económica adequada para comparar programas de saúde para tratar diferentes patologias.

Por outro lado, as sociedades modernas exigem cada vez mais que as tecnologias de saúde adoptadas pelos agentes nos sistemas de saúde, para além de prolongarem a vida aos destinatários dessa tecnologia, apresentem também um efeito na qualidade de vida geral ou pelo menos na qualidade de vida relacionada com a saúde. Assim, é fundamental que a unidade de medida que se adopta para avaliar o impacto das tecnologias de saúde tenha em consideração este duplo objectivo dos indivíduos, que é o prolongamento dos anos de vida e a qualidade com se vivem esses anos de vida ganhos. Acresce a este argumento que, de facto, muitas das tecnologias propostas afectam a mortalidade e, principalmente, a morbilidade, que por sua vez afecta a qualidade de vida.

Assim, a combinação das limitações associadas às unidades naturais como medidas de efectividade das consequências dos programas de saúde, com a necessidade de incluir a dimensão de qualidade de vida na avaliação do efeito das tecnologias de saúde, levou os investigadores a procurarem o desenvolvimento de unidades de medida que incorporem as duas dimensões de interesse: quantidade e qualidade de vida. Essa unidade de medida é o QALY - Quality Adjusted Life Yearque representa os anos de vida ganhos ponderados pela qualidade de vida relacionada com a saúde. Portanto, os QALY representam uma proposta de uma métrica que permite ao analista avaliar o efeito dos programas de saúde nas dimensões quantidade e qualidade de vida, agregados em apenas um índice.

Numa definição rápida, um determinado número (por exemplo, Y) de QALYs correspondem a viverY anos num estado de saúde ideal que, na opinião do indivíduo, valem tanto como viver $\mathrm{T}(>\mathrm{Y})$ anos de vida num estado de saúde inferior ao ideal. ${ }^{4} \mathrm{O}$ conceito de QALY e a sua pertinência como medida para avaliar comparativamente o efeito de diferentes tecnologias de saúde com diferentes e múltiplos efeitos pode ser compreendido através de um exemplo:

A quantos QALY correspondem 10 anos de vida passados num determinado estado de saúde, seja $\mathrm{H}_{1}$ esse estado de saúde, que se assume constante ao longo de 


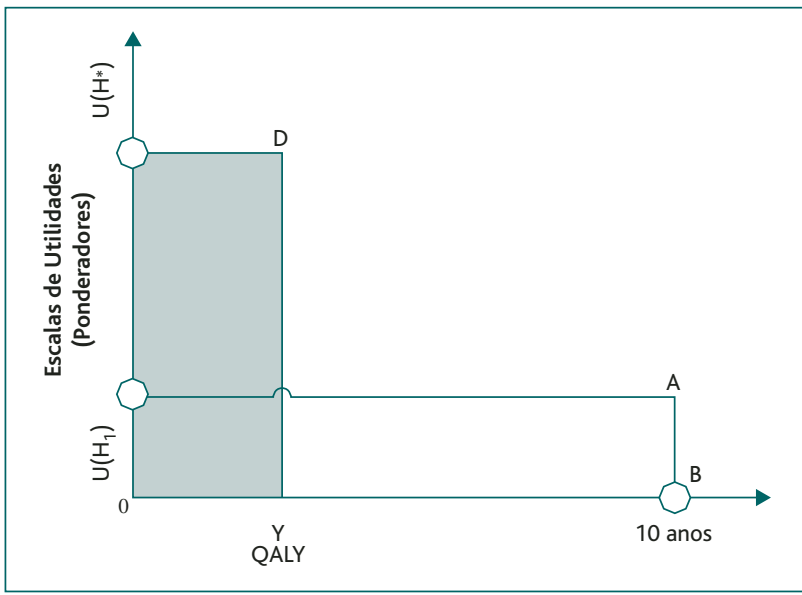

Figura 2. Relação entre qualidade de vida relacionada com a saúde, anos de vida e QALYs.

um período de tempo e conhecido? A resposta é que correspondem a um número $\mathrm{Y}(<10)$ de anos vividos num estado de saúde ideal (seja $\mathrm{H}^{*}$ esse estado de saúde) que o indivíduo considera valer tanto como os 10 anos vividos no estado de saúde $\mathrm{H}_{1}$. A Figura 2 ajuda a ilustrar o conceito.

A utilidade de 10 anos vividos no estado de saúde hipotético $\mathrm{H}_{1}$ corresponde à área $\boldsymbol{O} \times \boldsymbol{U}\left(\boldsymbol{H}_{1}\right) \times \boldsymbol{A} \times \boldsymbol{B}$. A mesma utilidade pode ser obtida por viverY $(<10)$ anos num estado de saúde designado como ideal, correspondente à área $\boldsymbol{O} \times \boldsymbol{Y} \times \boldsymbol{D} \times \boldsymbol{U}\left(\boldsymbol{H}^{*}\right)$. Assim, o número de QALYs correspondentes a 10 anos vividos no estado de saúde $\mathrm{H}_{1}$ é dado por $\mathrm{Y}(<10)$, número esse que varia de indivíduo para indivíduo em função das suas preferências. A questão agora está em encontrar um modo simples de obter a quantos QALYs correspondem os 10 anos de vida no estado de saúde $\mathrm{H}_{1}$. Na Figura 2, se se considerar que $\mathrm{U}\left(\mathrm{H}^{*}\right)=1 \mathrm{e} \mathrm{U}$ (Morte) $=0$, é simples verificar que $Y Q A L Y s=U\left(H_{1}\right) * 10$. Como veremos adiante, a escala de medida da Figura 2 é uma escala intervalar, onde se admite que um estado de saúde ideal tem uma utilidade de 1 e a morte uma utilidade 0. Portanto, os QALYs são obtidos ponderando os anos de vida (10 no exemplo anterior) por um ponderador que reflecte a qualidade de vida relacionada com a saúde do estado de saúde $\mathrm{H}_{1}$, para o período de referência (no exemplo anterior, $U\left(H_{1}\right)$ é esse ponderador). Os ponderadores que aparecem no eixo das ordenadas devem basear-se nas preferências dos indivíduos por diferentes estados de saú- de. Deste modo, a melhores estados de saúde correspondem ponderadores de valores mais elevados, sendo estes estados de saúde favorecidos na análise. ${ }^{1}$

Fica assim clara a vantagem da unidade de medida QALY como conveniente para avaliar comparativamente o efeito de diferentes programas de saúde que potencialmente influenciam de modo diverso o estado de saúde dos destinatários. Os QALYs, ao representarem o equivalente ao número de anos vividos num estado de saúde que se admite ideal, tornam o efeito de diferentes tecnologias de saúde comparável entre eles. Naturalmente que a maior dificuldade na mensuração do efeito das tecnologias de saúde em QALYs está em estimar o valor dos ponderadores necessários, os quais, como se afirmou, têm de se basear nas preferências dos indivíduos por diferentes estados de saúde. Mais adiante nesta secção veremos, ainda que de modo breve, alguns métodos para estimar esses pesos.

Vejamos de seguida, recorrendo a um exemplo prático, como calcular os QALYs ganhos correspondentes a um programa de saúde hipotético. Admita-se o seguinte cenário, ainda que muito simplificado, e de natureza determinística: assume-se que a população destinatária do programa de saúde apresenta um estado de saúde $\mathrm{H}_{1}$ (por exemplo, dificuldades de locomoção e alguma dor), sendo a qualidade de vida relacionada com a saúde avaliada em 0,6 numa escala $0-1$. Sem intervenção, o estado de saúde da população degrada-se e ao fim do primeiro mês a qualidade de vida relacionada com a saúde diminui, sendo avaliada em 0,4 . Este estado de saúde permanece assim até ao fim do primeiro ano, em que os indivíduos morrem ou deixa de fazer sentido serem seguidos. Com a introdução do programa de saúde os indivíduos conseguem preservar o estado de saúde inicial $\mathrm{H}_{1}$, durante 18 meses, tempo após o qual este se degrada, passando a ser avaliado com um score de 0.3. Permanecem nesse estado de saúde por mais 6 meses, tempo após o qual morrem ou deixa de fazer sentido serem seguidos. Os QALY ganhos por aplicação do programa são dados por $Q A L Y_{G}=$ $Q A L Y_{\text {Inter }}-Q A L Y_{\text {sem_inter }}$ onde $\mathrm{QALY}_{\mathrm{G}}$ designa os QALYs ganhos por implementação do programa de saúde relativamente à prática médica corrente, $\mathrm{QALY}_{\text {Inter }}$ designa os QALYS decorrentes da aplicação da tecnologia

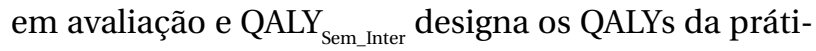
ca médica corrente. 


$$
\begin{gathered}
\text { PALY } Y_{\text {Inter }}=\begin{array}{c}
\text { Peso } \quad 18 \text { meses } \quad \text { Peso } \quad 6 \text { meses } \\
0,61,5+0,3 \times 0,5=1,05
\end{array} \\
Q A L Y_{\text {Sem_Inter }}=0,6 \times \frac{1}{12}+0,4 \times \frac{11}{12}=0,42 \\
Q A L Y_{\text {Inter }}-Q A L Y_{\text {Sem_Inter }}=0,63 \text { QALY ganhos }
\end{gathered}
$$

Portanto, a aplicação deste programa de saúde permite ganhos de 0,63 QALYs por indivíduo. Neste exemplo não considerámos qualquer taxa de actualização para descontar ganhos obtidos no futuro.

Como ficou patente até este ponto, para quantificar os QALYs de um programa de saúde é necessário determinar o efeito do programa de saúde nos anos de vida ganhos e na qualidade de vida relacionada com a saúde, por período. A dimensão qualidade de vida relacionada com a saúde deve reflectir as preferências individuais por diferentes estados de saúde. Assim, de seguida, abordaremos algumas questões relativas à medição das preferências individuais por estados de saúde.

É importante notar que neste texto não é nosso objectivo enumerar nem analisar as muitas dificuldades (resultantes de controvérsias metodológicas, de recolha e análise de dados, etc.) inerentes ao desenvolvimento de escalas e à consequente medição de conceitos tão abrangentes, intangíveis e multidimensionais como estado de saúde, qualidade de vida, qualidade de vida relacionada com a saúde. Este tem sido o propósito de muitos autores desde há longo tempo. ${ }^{1,5-8} \mathrm{Em}$ Portugal também há autores que se dedicam ao estudo desta área. ${ }^{9-11} \mathrm{O}$ nosso propósito neste texto é apenas o de mostrar algumas opções metodológicas disponíveis que têm sido utilizadas em estudos de avaliação económica e ilustrar como estas se podem utilizar da maneira mais adequada.

As preferências dos indivíduos por estados de saúde são avaliadas utilizando o conceito de utilidade (de estado de saúde), que Torrance ${ }^{5}$ define como sendo valores cardinais atribuídos a cada estado de saúde numa escala intervalar que é estabelecida de modo a que o estado de saúde ideal tenha uma utilidade de 1 e a morte uma utilidade de 0 . Alguns autores utilizam o conceito de Valor como sinónimo de Utilidade (de estado de saúde). Tecnicamente, Utilidade eValor representam conceitos diferentes. A obtenção de uns ou de outros depende das técnicas utilizadas na medição, nomeadamente da forma como se descrevem e formulam as questões durante o processo de medição. ${ }^{1,5}$ As utilidades obtidas são números que representam a intensidade de preferência por determinados estados de saúde que resultam da tecnologia de saúde em avaliação. Assim, na medição das utilidades, uma etapa preliminar que tem de ser cumprida é a descrição, ao indivíduo, dos estados de saúde relevantes que resultam das tecnologias de saúde em avaliação. Após essa descrição aos doentes, as utilidades (preferências cardinais pelos estados de saúde descritos) podem ser obtidas através de várias técnicas disponíveis para o efeito, nomeadamente Rating Scale (RS), Standard Gamble (SG) e Time Trade-Off(TTO). Uma descrição completa e detalhada de cada uma das técnicas, e modos como estas métricas devem ser utilizadas para medir as preferências, pode ser encontrada em Torrance, ${ }^{5}$ Brazier, ${ }^{8}$ Dolan ${ }^{6}$ e Ferrei$\mathrm{ra}^{11}$ entre outros.

A medição das utilidades através de um dos métodos directos referidos atrás tem-se revelado uma tarefa difícil e muito dispendiosa, principalmente a nível do tempo exigido para efectuar a medição, que exige múltiplas interacções com o doente. Como resultado destas dificuldades, a sua adopção para medir as utilidades e em consequência os QALYs, associados ao efeito das tecnologias de saúde não tem sido muito comum em estudos aplicados de avaliação económica. Em alternativa, estas têm sido avaliadas, indirectamente, através da utilização de sistemas de classificação multi-atributo de estados de saúde, desenvolvidos e validados para o efeito. São sistemas de classificação de estado de saúde, desenvolvidos a partir da teoria Multi-atributo da Utilidade, que incorporam explicitamente o carácter multidimensional do conceito saúde, inquirindo o indivíduo, através da administração de questionários, em várias dimensões de estado de saúde (dimensão física, dimensão social, dimensão mental, dimensão de mobilidade, etc.) que variam em função do instrumento adoptado. Da aplicação destes instrumentos aos doentes resulta a medição de um perfil de saúde multidimensional, que não é passível de ser utilizado como meio para avaliar o efeito das tecnologias de saúde em termos de QALYs.

Para que estes instrumentos de avaliação multi-atributo sejam úteis em estudos de avaliação económica é 
necessário que deles seja possível calcular um índice único, que reflicta a utilidade do estado de saúde decorrente da aplicação da tecnologia de saúde. Esta transposição de um perfil de saúde para uma escala intervalar que represente as valorações em termos de utilidade é efectuada através de algoritmos que foram desenvolvidos para cada instrumento de medição, tendo como base valorações de estado de saúde obtidas através dos métodos directos, tais como TTO e SG. Os instrumentos (escalas) de medição de estado de saúde mais conhecidos, e que são valorativos, isto é permitem, através de um algoritmo adequado, calcular uma utilidade cardinal que reflecte a utilidade do estado de saúde do indivíduo, são o EuroQol - EQ-5D http://www.euroqol.org, ${ }^{12,15}$ Health Utility Index - HUI [http://www.fhs. mcmaster.ca/hug], Quality ofWell-Being Scale-QWB ${ }^{13}$ e o SF-6D. ${ }^{7,9,11}$ Um exemplar do SF-6D adaptado e validado para Portugal pode ser encontrado em Ferreira e Ferreira. ${ }^{9}$

Como exemplo ilustrativo, que permitirá clarificar alguns aspectos, vamos aqui apresentar brevemente a escala de medição EuroQol. Este é um sistema de classificação multi-atributo de estado de saúde que assenta em 5 atributos básicos: (a) Mobilidade, (b) Cuidados Pessoais, (c) Actividades Correntes, (d) Dor/Desconforto, (e) Ansiedade/Depressão. Cada atributo apresenta três níveis: (1) sem dificuldades, (2) algumas dificuldades (3) grandes dificuldades. Assim, o sistema consegue distinguir 243 estados de saúde, aos quais os autores adicionaram mais dois, inconsciente e morto, conseguindo o sistema identificar 245 estados de saúde possíveis. O algoritmo para determinar as utilidades associadas a cada um desses 245 estados de saúde foi desenvolvido através da especificação de modelos econométricos e as preferências base, que foram objecto de análise, foram obtidas de uma amostra aleatória de 3.000 indivíduos adultos residentes no Reino Unido através da técnica Time Trade-Off. ${ }^{14}$

O indivíduo responde ao inquérito e identifica, para cada dimensão de estado de saúde considerada na escala, a situação que melhor descreve a sua saúde actual, em termos de: 1) sem dificuldades, 2) algumas dificuldades 3 ) grandes dificuldades, resultando daqui, e para cada respondente, um conjunto de 5 dígitos (um para cada dimensão de saúde do questionário) que reflecte o perfil de estado de saúde do indivíduo. Por exemplo o estado de saúde 11111 indica que o indivíduo não tem problemas em nenhuma das 5 dimensões de saúde. Por outro lado, o estado de saúde 11223 indica que nas dimensões Mobilidade e Cuidados Pessoais o indivíduo não apresenta quaisquer dificuldades, nas dimensões Actividades Correntes e Dor/Desconforto apresenta alguns problemas e por fim, na dimensão Ansiedade/Depressão, tem grandes dificuldades. $\mathrm{O}$ algoritmo de pontuação para determinar o índice de utilidade é de aplicação directa e imediata. Por exemplo, Dolan,,$^{15}$ que explica o algoritmo de pontuação em detalhe, mostra que para uma descrição de estado de saúde correspondente a 11223 o índice de utilidade correspondente é de 0,255. Assim, se uma tecnologia de saúde permitir ao indivíduo prolongar a sua vida em 10 anos com um perfil de estado de saúde, descrito pelo EQ-5D, de 11223 , isso equivaleria a um efeito de $10 * 0,255=2,55$ QALYs ganhos.

Apesar de os QALY serem a unidade de medida mais consensual e a que é geralmente adoptada para as ACU, não está isento de criticas. Os aspectos mais críticos reflectem em larga medida as dificuldades, metodológicas e de medição, em captar de modo preciso as utilidades/preferências individuais por estados de saúde. Este é um tema que tem sido objecto de amplo debate e investigação, mas que está para além do objectivo deste texto discutir. ${ }^{16-20}$

Como consequência da controvérsia que tem rodeado os QALY como unidade de medida apropriada para captar o duplo efeito - anos de vida ganhos e qualidade de vida - dos programas de saúde, têm surgido na literatura propostas de métricas alternativas para estimar o impacto das tecnologias de saúde. A título de exemplo refiram-se os Healthy-years equivalents (HYEs), ${ }^{21-24}$ os saved-young-life equivalents (SAVEs) ${ }^{25} \mathrm{e}$ os Disability adjusted life years (DALYs). ${ }^{26-29}$

\section{FONTES DE EVIDÊNCIA PARA ESTUDOS DE AVALIAÇÃO ECONÓMICA}

Para a realização de estudos de avaliação económica de serviços de Saúde são normalmente necessários três tipos de dados:

- Dados relativos a parâmetros epidemiológicos da doença ou fenómeno que se pretende estudar, sendo importante que prevalência e incidência sejam as que se verificam na região geográfica a que se refere 
o estudo em causa;

- Dados relativos à efectividade das tecnologias/estratégias médicas em confronto;

- Dados relativos às características da prática médica. Sempre que possível, os elementos estatísticos epidemiológicos devem ser obtidos a partir de estudos de base populacional. Na sua ausência, poderão ser utilizados estudos epidemiológicos de base hospitalar ou outra, desde que correctamente ponderados. Se não existir disponibilidade de estatísticas desta natureza, poderão ser utilizados como estimativas dados de regiões, desde que esse facto seja tratado com a devida prudência. Em qualquer caso, a proveniência dos dados utilizados e as hipóteses assumidas deverão ser claramente especificadas.

Os dados sobre a efectividade são normalmente os mais importantes para os estudos de avaliação económica. Como este tipo de trabalhos normalmente é realizado sobre procedimentos ou serviços de prática clínica corrente, é extremamente relevante que a informação neles utilizada reflicta a realidade nacional.

O ensaio clínico controlado e aleatorizado é o método mais robusto para determinar uma relação de causalidade e, portanto, avaliar a eficácia ou efectividade de intervenções terapêuticas. Como tal, deve-se privilegiar sempre a informação proveniente de ensaios clínicos ou de meta-análises de ensaios clínicos com estas características. As meta-análises são uma técnica de revisão sistemática da literatura que envolve o levantamento e tratamento estatístico de todos os trabalhos relevantes, cuja qualidade é avaliada de um modo rigoroso e segundo modelos pré-definidos.

$\mathrm{Na}$ impossibilidade de se dispor de dados nas condições referidas, é admissível a utilização de dados de eficácia obtidos em ensaios clínicos adequados, corrigidos por modelização. Também é aceitável a utilização de dados de efectividade obtidos a partir de estudos epidemiológicos observacionais. Os dados recolhidos prospectivamente são preferíveis aos obtidos retrospectivamente. Em qualquer dos casos a realidade nacional deve estar reflectida e a justificação das opções deve ser exaustiva. A opção menos robusta para o cálculo da efectividade é a utilização de um painel de peritos, que deve ser considerada apenas como último recurso e deverá ter por base dados de eficácia obtidos em ensaios clínicos. Ou seja, um painel de peritos não pode avaliar a eficácia - apenas poderá estimar a efectividade a partir de dados de eficácia reais. A única excepção a esta regra são as doenças, síndromas ou situações de baixa prevalência e incidência («estratégias órfãs»), o que impossibilita logisticamente a realização de ensaios clínicos.

Os estudos de avaliação económica devem reflectir a prática médica corrente na região a que se referem, em especial no que respeita à identificação de tecnologias/ estratégias médicas que aí têm real expressão, isto é, que são mais utilizadas. Por exemplo, saber a propósito do tratamento da hipertensão qual é o medicamento mais frequentemente escolhido como terapêutica de primeira linha, ao fim de quanto tempo são procuradas alternativas terapêuticas, qual a frequência da associação medicamentosa e que medicamentos são mais frequentemente associados.

Assim, na realização de estudos de avaliação económica de tecnologias de saúde serão privilegiados os resultados obtidos a partir de ensaios clínicos metodologicamente válidos e com relevância para o país. Admitem-se também outras fontes de dados, desde que estas sejam claramente justificadas e validadas. Em todos os casos deve-se demonstrar que a população abrangida pelos estudos clínicos é representativa da população alvo.

\section{PAPEL E RELEVÂNCIA DOS MODELOS DE DECISÃO NA EXECUÇÃO DE UMA AVALIAÇÃO ECONÓMICA}

$\mathrm{O}$ ambiente real em que os agentes de decisão têm de escolher entre opções alternativas é, regra geral, muito complexo. Esta complexidade, que é norma em qualquer outro domínio de actividade humana, e em particular, no domínio da afectação de recursos no sector da saúde, deriva da existência de múltiplos actores, de múltiplas variáveis e ainda da existência de múltiplas interacções entre todos estes elementos. Uma abordagem científica de apoio à tomada de decisão tem por objectivo encontrar um conjunto de procedimentos sistematizados, organizados e tecnicamente bem sustentados que permitam escolhas com qualidade e justificadas, dada a evidência disponível no momento da tomada de decisão. Esta abordagem científica consegue-se através do desenvolvimento de um modelo de apoio à resolução de problemas e à tomada de decisão que, em geral, envolve as seguintes etapas: 
1) Definição do problema;

2) Construção e desenvolvimento de um modelo;

3) Selecção, identificação e recolha de dados;

4) Resolução/estimação do modelo;

5) Análise da robustez da solução;

6) Implementação e controlo da solução.

Uma avaliação económica de programas de saúde corresponde à resolução de um problema num ambiente de tomada de decisão que se caracteriza pela sua complexidade e que, basicamente, consiste em averiguar se um novo programa de saúde traz vantagens terapêuticas e económicas relativamente a nada fazer ou à prática clínica corrente, pelo que a construção de modelos de apoio à decisão, de vários tipos, se tem revelado útil no domínio das avaliações económicas.

$\mathrm{Na}$ avaliação económica de programas de saúde, os modelos matemáticos são utilizados em duas situações gerais: em primeiro lugar, quando não existem ensaios clínicos relevantes que forneçam dados, nem de efectividade nem económicos. Nestas circunstâncias, os modelos são a ferramenta adequada para sintetizar e combinar a evidência disponível proveniente de várias fontes. Em segundo lugar, os modelos são ainda usados nas situações em que existem ensaios clínicos relevantes que fornecem dados de efectividade e económicos, mas que apenas medem as consequências do programa de saúde em unidades de medida intermédia ou seguem os doentes por curtos períodos de tempo. Nestas circunstâncias são utilizados modelos estatísticos para dois tipos de extrapolação: das consequências intermédias para consequências finais e ainda para extrapolar para além do horizonte temporal da experiência. ${ }^{30}$ Uma outra situação em que a modelação é necessária, mesmo na presença de dados provenientes de ensaios clínicos, é quando o programa de saúde que serve de comparador não foi objecto de estudo no âmbito de um ensaio clínico. Por exemplo, na avaliação económica de um medicamento inovador, que é objecto de um ensaio clínico com os dados de efectividade e de custo relevantes, os modelos são utilizados para avaliar os custos e consequências da prática clínica corrente, que não foi objecto do ensaio clínico.

Para determinados efeitos, principalmente pedagógicos, as avaliações económicas podem ser classificadas em análises custo-efectividade/utilidade estocásticas ou em análises custo-efectividade/utilidade ba- seadas em modelos. Nos casos em que as avaliações económicas são baseadas em dados de efectividade e de custos a nível individual (geralmente provenientes de ensaios clínicos) as análises são denominadas de análises custo-efectividade/utilidade estocásticas. Por outro lado, avaliações económicas baseadas no desenvolvimento de um modelo de decisão para combinar e sintetizar a evidência proveniente de diversas fontes são geralmente denominadas de análises custo-efectividade/utilidade baseada em modelos. ${ }^{31}$ Contudo, convém referir que esta dicotomia pura entre análises estocásticas e as baseadas em modelos raramente tem correspondência na realidade das análises, pois muito poucos estudos de avaliação económica são puramente estocásticos, havendo sempre necessidade de recorrer a análises baseadas na modelação. ${ }^{30}$

Etapas do desenvolvimento de um modelo de avaliação económica

A Figura 3 mostra as etapas de desenvolvimento de um modelo de apoio à tomada de decisão para problemas de avaliação económica. ${ }^{1,32,33}$

\section{Definir e especificar o problema de decisão}

A primeira etapa na resolução de um problema de avaliação económica é a cuidadosa e clara definição e especificação do problema de decisão. Uma definição cuidadosa é crucial pois, a menos que se dispense algum tempo e cuidado nesta fase, poderemos estar a tentar resolver o problema errado. Esta etapa envolve, pelo menos, a verificação dos seguintes pontos: identificação e descrição genérica das metas a atingir pelo estudo; perspectiva a adoptar (sociedade, terceiro pagador, hospital, etc.); identificação do(s) grupo(s) alvo e características dos indivíduos que o compõem; descrição completa e detalhada de todos os programas de saúde em avaliação; descrição do contexto em que os cuidados de saúde decorrentes da aplicação dos programas vão ser aplicados (cuidados primários, hospital, aplicados pelo prestador, etc.); definição da unidade de medida a utilizar para medir as consequências dos programas de saúde; horizonte temporal, etc.

\section{Estruturar e desenvolver um modelo de decisão}

A segunda etapa no desenvolvimento de um modelo de apoio à decisão para execução de um estudo de avalia- 


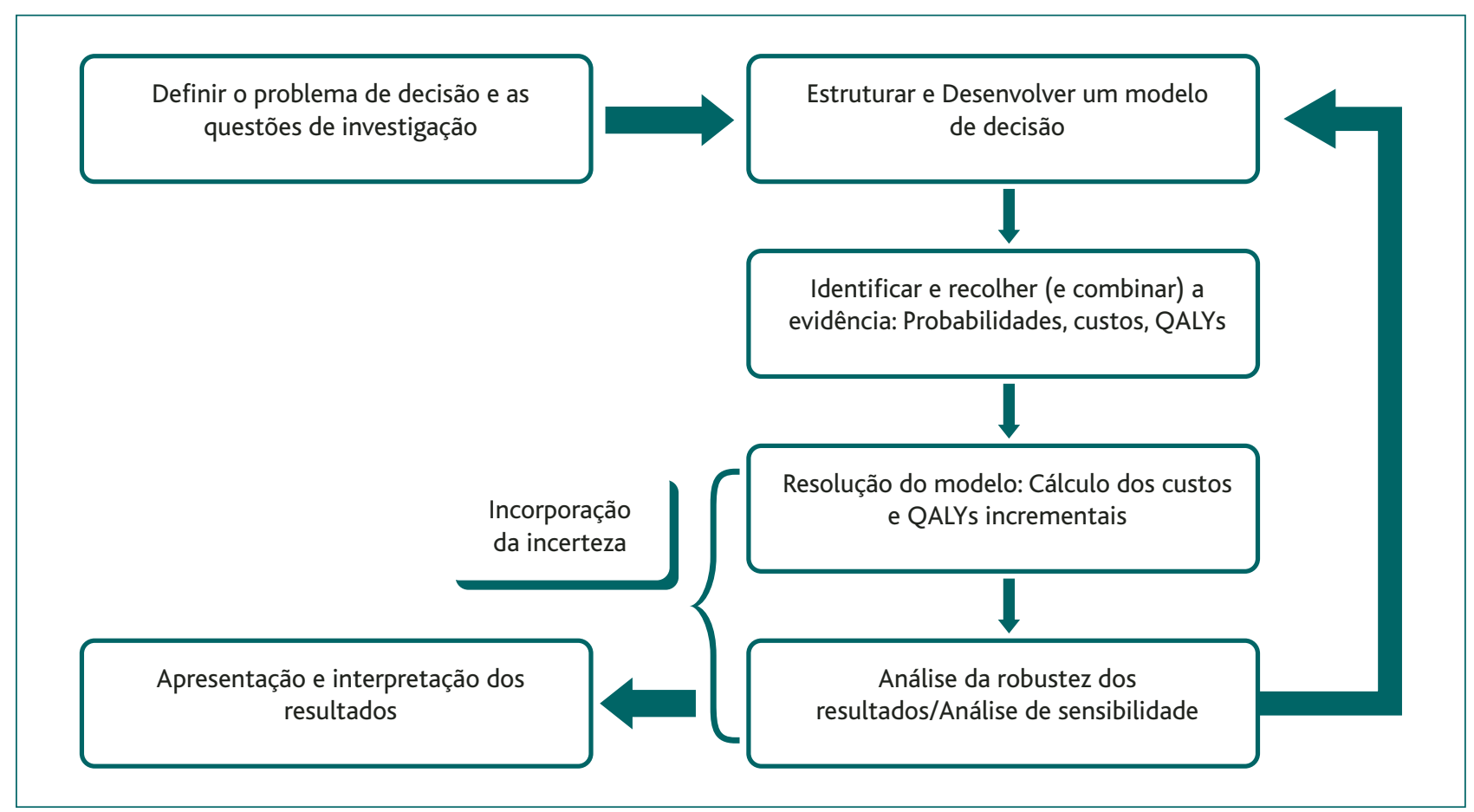

Figura 3. Etapas do desenvolvimento de um modelo de apoio à decisão para execução de um estudo de avaliação económica.

ção económica corresponde à estruturação de um modelo analítico que permita incorporar na análise todas as especificidades inerentes ao problema em análise.

A palavra modelo é usada para designar qualquer representação, usualmente simplificada, de um objecto ou fenómeno que se verifica no mundo real, podendo ser um sistema ou um processo. Os modelos são modos de representar a complexidade do mundo real de uma forma simples e compreensível. No contexto da avaliação económica de programas de saúde, um modelo pode ser definido como qualquer estrutura, matemática, esquemática, etc., que represente os custos e consequências das diversas alternativas em análise, sob uma variedade de cenários. ${ }^{34}$

A estrutura destes modelos não é pré-especificada pelo agente de decisão, sendo escolhida pelo analista de entre um amplo leque de opções, de modo a reflectir as necessidades do problema em análise. Esta é desenvolvida com base no que se conhece da natureza da progressão da doença e do impacto de cada uma das alternativas nessa progressão, tendo sempre em mente organizar, de modo coerente, as possíveis conse- quências dos programas de saúde em avaliação.

A prossecução desta etapa pode revelar-se difícil, pois não é possível estabelecer regras de aplicação universal. Cada problema de avaliação económica apresenta as suas especificidades, donde a sua estruturação requerer soluções criativas da parte do investigador. Apesar de existir uma variedade de opções de modelação para estruturar os problemas de avaliação económica - Brennan et a $l^{35}$ apresentam uma taxonomia para estas estruturas - a maioria das avaliações estruturam o modelo de decisão esquematicamente utilizando árvores de decisão ${ }^{36}$ ou modelos de Markov. ${ }^{37,1,33}$ Karnon $^{37}$ refere que numa análise a 119 artigos na área da avaliação económica aplicada, $64 \%$ dessas aplicações utilizaram árvores de decisão como modelo de análise e 36\% adoptaram modelos de Markov como metodologia de análise. Apenas dois artigos utilizaram a técnica de simulação por acontecimentos discretos para estruturar o problema de decisão.

Um aspecto que deve também ser considerado nesta fase é a apresentação clara das hipóteses em que o modelo assenta, de modo a balizar o alcance deste e a 
que o agente de decisão possa avaliar a qualidade do modelo. Este é um aspecto importante, pois se o modelo assentar em hipóteses muito restritivas e inverosímeis e que não reflictam adequadamente algum aspecto de evolução da doença ou do comportamento dos agentes envolvidos no programa de saúde (doentes, prestadores, etc.), então os resultados do modelo serão inválidos e a decisão incorrecta. Como veremos adiante, uma das críticas de que têm sido alvo as avaliações económicas baseadas em modelos de decisão é que estes tendem a representar uma realidade muito simplificada, por via das hipóteses em que se baseiam. Como um modelo é um compromisso entre a realidade que pretende representar e a sua facilidade de uso, as hipóteses são necessárias. Contudo, estas têm de ser adequadamente explicitadas para que terceiros possam analisar e avaliar as suas implicações nos resultados finais.

\section{Identificar, recolher e combinar a evidência: probabilidades, custos, QALYs}

Após a validação da estrutura do modelo, efectuada na etapa anterior, é necessário identificar e recolher os itens de informação necessários para o estudo (medidas de efectividade, utilidades, QALYs, custos unitários, custos totais, etc.) e combiná-los para gerar os parâmetros/inputs do modelo (probabilidades de eventos clínicos e outros, custos de cada opção, efectividade/QALY de cada alternativa, etc.).

A Secção Fontes de evidência para estudos de avaliação económica descreve as fontes de evidência para executar estudos de avaliação económica, bem como os cuidados que o analista deve ter em consideração, apresentando ainda uma hierarquia para avaliar a qualidade da evidência em função da fonte.

\section{Resolução do modelo: cálculo das consequências, custos e resultados incrementais}

Após a definição e estruturação do modelo e do respectivo «preenchimento» com os inputs necessários e determinados na etapa anterior, o passo seguinte é o cálculo dos custos e das consequências em termos de efectividade, QALYs, etc., de cada um dos programas de saúde em avaliação. Após o cálculo dos custos e das consequências de cada um dos programas de saúde, o analista está em condições de calcular os rácios incre- mentais custo-efectividade. Estes rácios são indicadores que relacionam custos e consequências dos programas de saúde e têm sido utilizados para elaborar as recomendações finais em estudos de avaliação económica. A secção seguinte descreve estes rácios: como se calculam, o que significam e como se interpretam, argumentando de seguida que estes são os outputs dos estudos que se devem ter em conta na tomada de decisão.

Esta etapa envolve por vezes cálculos complexos que requerem a utilização intensiva de poder computacional, principalmente nos casos em que se incluem nesta etapa os aspectos de incerteza presentes em estudos de avaliação económica.

\section{Análise da robustez dos resultados/Análise de sensibilidade}

Caso não se incorpore os aspectos de incerteza na etapa de resolução do modelo, todos os parâmetros resultantes da estimação do modelo são assumidos como determinísticos, representando portanto o valor verdadeiro para uma determinada circunstância. Esta hipótese de certeza no valor dos resultados finais do modelo deve ser questionada dada a muito provável imprecisão que rodeia todas as questões metodológicas associadas à condução de um estudo de avaliação económica (especificação do modelo de decisão, identificação e medição de custos e de consequências, insuficiência dos dados disponíveis, etc.). Assim, as avaliações económicas de programas de saúde devem ter em consideração que alguns inputs do modelo são estimados com base em dados sujeitos a um determinado grau de incerteza. Deste modo, o efeito da incerteza nos resultados finais e, em consequência, na qualidade das decisões, deve ser tido em consideração. É para atingir este propósito que é boa prática a execução de análises de sensibilidade. $O$ tratamento da incerteza no âmbito dos estudos de avaliação económica será objecto de uma subsecção autónoma e analisado mais adiante neste texto.

\section{O Valor da modelação}

O valor da modelação e dos modelos de apoio à tomada de decisão no contexto da avaliação económica em saúde é reconhecido nos seguintes aspectos:

- Garantem que todas as alternativas relevantes são 
comparadas;

- Permitem incluir, combinar e sintetizar toda a evidência disponível, geralmente proveniente de diversas fontes;

- Permitem extrapolar de consequências intermédias para consequências finais;

- São um meio para extrapolar as consequências para um horizonte temporal apropriado;

- São um meio para incorporar os elementos de incerteza que caracterizam diversos aspectos no desenvolvimento de avaliações económicas;

- E, por fim, os modelos de apoio à decisão permitem ainda viabilizar a extrapolação das consequências dos programas de saúde (efectividade/QALYs) para o contexto real em que esses programas vão ser implementados. ${ }^{1,32}$

\section{O tratamento da incerteza nos estudos de avaliação económica}

Todas as avaliações económicas contêm vários elementos de incerteza com origem em dados insuficientes e, por vezes, pouco fiáveis, controvérsias metodológicas, etc. Por exemplo, na execução de uma avaliação económica o analista combina informação de diversa natureza e proveniente de diversas fontes, por exemplo, custos unitários de várias classes de recursos, quantidade de recursos utilizados, anos de vida ganhos, valores de utilidade que reflectem a qualidade de vida relacionada com a saúde, probabilidades de ocorrência de eventos clínicos decorrentes da doença ou do processo de tratamento, entre outros. Para alguns destes itens de informação o analista pode ter um grau de certeza elevado de que este reflecte o seu verdadeiro valor; contudo, existem muitos outros dados para os quais é limitada a certeza de que a informação recolhida é estimada com precisão. Esta incerteza, relativamente ao verdadeiro valor de alguns dados base, vai ter efeitos no cálculo dos resultados finais resultantes da avaliação económica (custos totais e QALYs ganhos de cada programa de saúde). Estes irão ser parâmetros finais sujeitos a um determinado grau de incerteza. Por exemplo, os QALY ganhos de um programa de saúde são função dos anos de vida ganhos, da utilidade de cada estado de saúde sob esse programa e de probabilidades que reflectem a progressão da doença e a resposta ao tratamento, ou seja $Q A L Y=Q\left[\right.$ Anos_Vida, $\left.U\left(h_{i}\right), P_{j}\right]$. Se os argumentos desta função estiverem sujeitos a incerteza, também o resultado final vai estar contaminado com um determinado grau de incerteza.

Naturalmente, a incerteza pode influenciar os resultados finais das avaliações económicas, pelo que todos os estudos aplicados devem incorporar explicitamente elementos de incerteza nas análises com o objectivo de explorar e de avaliar o seu impacto nas decisões a que as avaliações económicas conduzem. A título de exemplo, refira-se que a linha de orientação do INFARMED para a execução de avaliações económicas de medicamentos indica explicitamente que «deve ser realizada uma análise de sensibilidade aos parâmetros de input cujos valores estejam sujeitos a incerteza». ${ }^{38}$

A incerteza acima identificada é a relativa aos parâmetros de input do modelo, contudo, as análises custo-efectividade e custo-utilidade apresentam outros tipos e fontes de incerteza, cuja identificação e classificação está patente no Quadro III. Relativamente ao método mais adequado para incorporar explicitamente a incerteza nos estudos de avaliação económica, depende se estamos perante análises estocásticas ou análises baseadas em modelos, dependendo ainda da origem dessa incerteza. ${ }^{31,39}$

\begin{tabular}{|c|c|}
\hline \multicolumn{2}{|c|}{$\begin{array}{l}\text { QUADRO III. Fontes de incerteza e métodos para } \\
\text { a tratar em estudos de avaliações económicas. } \\
\text { Adaptação de Briggs. }{ }^{31}\end{array}$} \\
\hline Tipo de incerteza & $\begin{array}{l}\text { Método para lidar } \\
\text { com a incerteza }\end{array}$ \\
\hline \multicolumn{2}{|c|}{ Avaliações económicas estocásticas } \\
\hline Metodológica & Análise de sensibilidade \\
\hline Variação amostral & Análise estatística \\
\hline $\begin{array}{l}\text { Extrapolação (para horizontes } \\
\text { temporais alargados) }\end{array}$ & Métodos de Modelação \\
\hline $\begin{array}{l}\text { Generalização/transferência } \\
\text { para outros contextos }\end{array}$ & Análise de sensibilidade \\
\hline \multicolumn{2}{|c|}{ Avaliações económicas baseadas em modelos } \\
\hline Metodológica & Análise de sensibilidade \\
\hline $\begin{array}{l}\text { Incerteza nos parâmetros } \\
\text { de input }\end{array}$ & $\begin{array}{l}\text { Análise de sensibilidade } \\
\text { probabilística }\end{array}$ \\
\hline $\begin{array}{l}\text { Incerteza na estrutura } \\
\text { do modelo }\end{array}$ & Análise de sensibilidade \\
\hline $\begin{array}{l}\text { Generalização/transferência } \\
\text { para outros contextos }\end{array}$ & Análise de sensibilidade \\
\hline
\end{tabular}


Apesar dos diversos tipos de incerteza que caracterizam as avaliações económicas, no seguimento deste texto vamos explorar os métodos para a incorporar apenas para alguns desses tipos.

\section{Análises económicas estocásticas: variação amostral}

As análises económicas estocásticas têm dados individuais a nível de custos e de efectividade (provenientes de ensaios clínicos), que constituem uma amostra de uma determinada população alvo. Assim, como todas as estimativas de custos e de efectividade são calculadas com base nessa amostra, estão sujeitas a variação aleatória, ou seja, são estimadas com incerteza. Neste caso, a análise estatística fornece a metodologia adequada para incorporar e representar a incerteza nos resultados das avaliações económicas, sendo mesmo possível quantificar a magnitude da incerteza através do cálculo do desvio padrão. Neste contexto de dados podemos ainda proceder a testes de hipóteses, construir intervalos de confiança, etc. Por exemplo, numa amostra de doentes em que cada um deles apresenta um custo, podemos estimar o custo médio, porém, com um dado grau de imprecisão que pode ser quantificada pelo erro padrão da estimativa da média.

\section{Análises económicas baseadas em modelos: incerteza nos parâmetros de input}

Este é o tipo de incerteza que decorre da imprecisão subjacente aos dados que servem de base à estimação dos parâmetros de input dos modelos. É importante ter metodologias adequadas para avaliar o impacto da incerteza nos resultados finais das análises.

Um primeiro método consiste em proceder a análises de sensibilidade. O método consiste simplesmente em fazer variar os parâmetros que se consideram que foram estimados com imprecisão, e analisar a variação do resultado final da análise, por exemplo o rácio incremental custo-efectividade, em função da variação desse parâmetro. Se a decisão final não se alterar quando esses parâmetros variam dentro de determinados limites, então as conclusões podem ser consideradas robustas. Uma análise de sensibilidade envolve as seguintes decisões: 1) identificação dos parâmetros sujeitos a incerteza; 2) especificação dos limiares de variação dos parâmetros sujeitos a incerteza. Geralmente são apresentados o valor inferior e superior do parâmetro para os quais as decisões não se alteram.

As análises de sensibilidade apresentam algumas desvantagens, nomeadamente, não é possível considerar análises de sensibilidade que façam variar simultaneamente um elevado número de parâmetros de input. Uma outra desvantagem das análises de sensibilidade é nas situações em que os parâmetros estão correlacionados, sendo que estas ignoram os efeitos desta correlação estatística. Uma terceira desvantagem é que estas não apresentam uma medida sumária das implicações da incerteza. ${ }^{1,40}$

Dadas as limitações da análise de sensibilidade, uma forma alternativa e mais sofisticada de ter em consideração a incerteza patente nos parâmetros de input é a análise de sensibilidade probabilística. ${ }^{1,31,33,41}$ Basicamente consiste em admitir que os parâmetros de input do modelo sujeitos a incerteza seguem uma determinada lei de probabilidades para assim caracterizar completamente a forma dessa incerteza. A escolha da lei de probabilidade adequada para cada situação torna-se então uma questão metodológica importante e de impacto não negligenciável. Após a escolha da função de distribuição para caracterizar a natureza aleatória dos parâmetros de input, recorre-se a técnicas de simulação computacionais para avaliar o modelo (cálculo de resultados finais) um grande número de vezes (por exemplo 10.000). Em cada simulação e extrai-se um valor aleatória para cada um dos parâmetros de input, valor esse extraído da função de distribuição atrás referida. No final do processo de simulação o analista tem um número elevado de soluções (tantas quantas as corridas de simulação, 10.000 no nosso exemplo) em termos de custo e efectividade para cada um dos programas de saúde em avaliação. A etapa final na elaboração de uma análise de sensibilidade probabilística envolve a apresentação dos respectivos resultados, recorrendo a medidas sumárias e a gráficos que apresentam as múltiplas soluções, as obtidas por simulação computacional, no plano custo efectividade.

\section{Limitações e potencialidades dos modelos}

Até este ponto ficou patente que a modelação desempenha um papel relevante nos estudos de avaliação económica. Apesar da sua importância como instrumento de apoio às AES, existem algumas preocupações quanto à validade das conclusões a que estes permitem 
chegar. Há autores que referem que os modelos representam uma realidade muito idealizada, não reflectindo portanto as complexidades do mundo real, o que os leva a questionar pois a sua utilização nos estudos de avaliação económica. A titulo de exemplo, refira-se que o desenvolvimento de um modelo exige que o analista assuma um conjunto de hipóteses chave acerca do processo de doença, da dinâmica de tratamento, tem ainda de assumir hipóteses para efectuar extrapolações para horizontes temporais mais longos, etc. Para além disto, os dados podem apresentar enviesamentos de diversas naturezas e para os ultrapassar o analista tem de assumir hipóteses acerca desses desvios. Como consequência, existe um elevado grau de discricionariedade do analista na etapa de especificação de modelos em estudos de avaliação económica. ${ }^{30}$ Se os analistas não forem transparentes, não revelando o interior da «caixa negra» do modelo, podem existir, em nosso entender, legítimas suspeitas quanto à validade dos modelos no âmbito das avaliações económicas.

Na nossa opinião, os modelos não devem ser nem endeusados nem diabolizados, têm é de ser claros, transparentes e explícitos em todos os aspectos, de modo que o agente de decisão e outros analistas possam avaliar a respectiva qualidade. $O$ analista e agentes de decisão devem ser críticos relativamente a cada hipótese assumida e, acima de tudo, devem reflectir acerca do impacto de cada hipótese nas conclusões dos estudos. Os modelos representam simplesmente um meio para tentar ultrapassar as deficiências em termos de disponibilidade e características da informação (dados de custos e de efectividade/QALY) necessários para executar uma avaliação económica.

Para garantir homogeneidade na qualidade dos modelos desenvolvidos no âmbito das avaliações económicas e também a sua credibilidade como instrumento de apoio, vários autores têm analisado e discutido as características de um bom modelo. ${ }^{42-44}$

\section{ANÁLISE INCREMENTAL: O RÁCIO INCREMENTAL CUSTO-EFECTIVIDADE (ICER)}

A avaliação económica de tecnologias de saúde foi definida como a análise comparativa de duas ou mais tecnologias de saúde alternativas nos seus custos e resultados. O curso natural do processo de avaliação leva a que, após a identificação e medição dos custos e das consequências associados às tecnologias em avaliação, $o$ analista necessite de os relacionar para assim obter um indicador que facilite o input de informação. Por uma questão de clareza na apresentação das ideias expostas nesta secção, admita-se que o objectivo da avaliação económica é o de avaliar uma nova tecnologia, denominada por $\mathrm{T}_{1}$ comparativamente à prática clínica corrente, denominada por $\mathrm{T}_{0}$. $\mathrm{O}$ indicador que relaciona custos e consequências das tecnologias de saúde e que é adoptado com maior frequência para elaborar as recomendações finais em estudos de avaliação económica é o Rácio Incremental Custo-Efectividade (ICER-Incremental Cost-Effectiveness Ratio). Este é definido por pela seguinte expressão:

$$
I C E R=\frac{\left(C_{1}-C_{0}\right)}{\left(E_{1}-E_{0}\right)}=\frac{\Delta C}{\Delta E}
$$

$\mathrm{Na}$ equação anterior $\mathrm{C}_{1}$ e $\mathrm{C}_{0}$ representam, respectivamente, os custos associados às tecnologias $\mathrm{T}_{1} \mathrm{eT}_{0}$. Da mesma forma $\mathrm{E}_{1}$ e $\mathrm{E}_{0}$ medem, respectivamente, as consequências das tecnologias $\mathrm{T}_{1} \mathrm{e}_{0}$.

$\mathrm{O}$ numerador deste rácio representa o custo incremental de adoptar a tecnologia $\mathrm{T}_{1}$, em relação à $\mathrm{T}_{0}$, e o denominador mede o resultado incremental de adop$\operatorname{tar} \mathrm{T}_{1}$ em relação a $\mathrm{T}_{0}$. Assim, este rácio fornece-nos um indicador para o custo por unidade adicional de resultado que se espera que resulte de escolher $\mathrm{T}_{1}$ em relação a $\mathrm{T}_{0}$. Se a unidade de medida dos resultados das tecnologias for o QALY e o ICER for avaliado em, por exemplo $€ 100$, significa que cada QALY adicional obtido por adopção de $\mathrm{T}_{1}$, em relação a $\mathrm{T} 0$, apresenta um custo de $€ 100$.

Nos estudos de avaliação económica os rácios incrementais custo-efectividade são geralmente apresentados graficamente no plano $\Delta \mathrm{E}-\Delta \mathrm{C}$, possuindo uma interpretação geométrica interessante.

Admita-se que $\mathrm{T}_{0}$ é a tecnologia corrente ou comparadora, que apresenta efectividade total $\mathrm{E}_{0}$ e custo total $\mathrm{C}_{0}$, sendo esta representada no plano $\mathrm{E} \times \mathrm{C}$ no painel da esquerda da Figura 4. Assumam-se agora 4 cenários independentes relativamente aos custos e consequências da nova tecnologia, denominada, de modo alternativo, e para cada cenário, $\mathrm{T}_{1}, \mathrm{~T}_{2}, \mathrm{~T}_{3} \mathrm{e} \mathrm{T}_{4}$.

No cenário 1 a nova tecnologia $\mathrm{T}_{1}$, é mais efectiva do que a tecnologia corrente, apresentando contudo maiores custos. Nesta caso não é claro se a nova tecnologia 


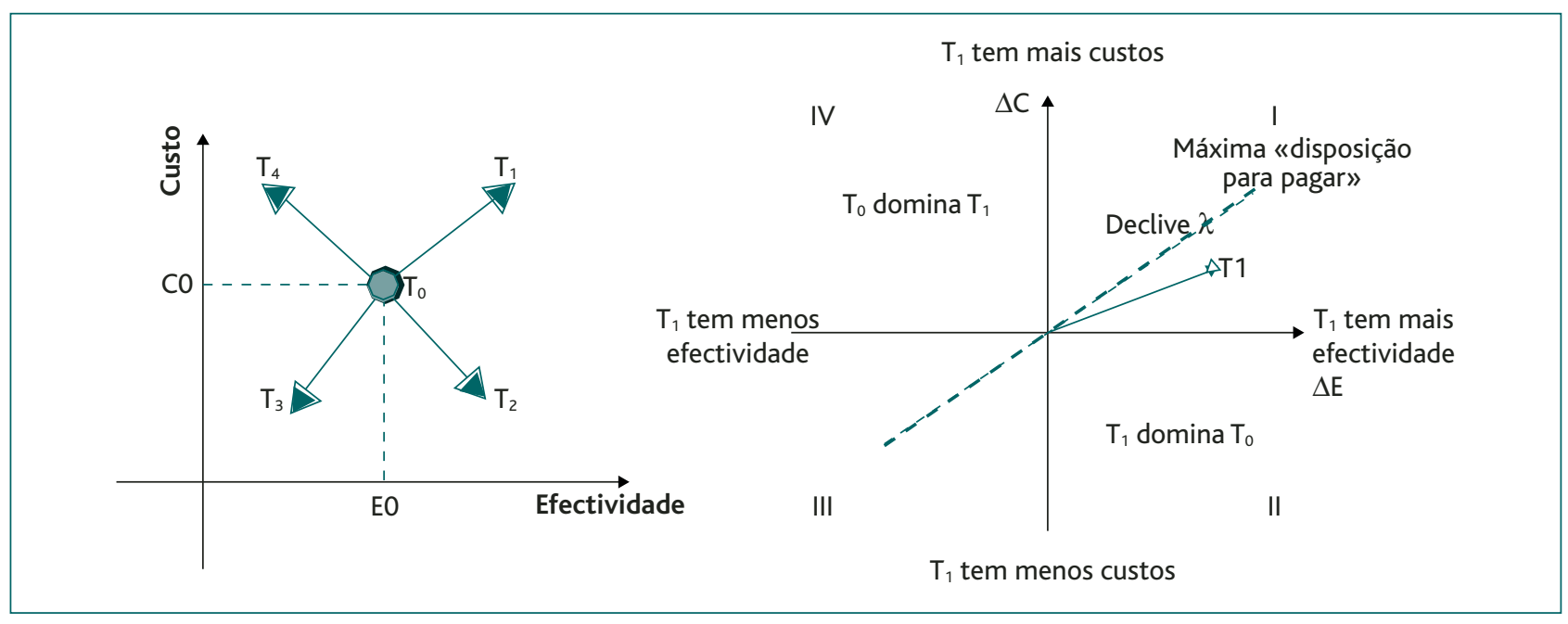

Figura 4. O Plano custo-efectividade

deve ou não ser adoptada, dependendo a decisão de quanto o agente de decisão está disposto a pagar por unidade de efectividade adicional ganha por adopção de $\mathrm{T}_{1}$, tendo neste caso de se recorrer ao cálculo do ICER. No cenário 2 a nova tecnologia $\mathrm{T}_{2}$, é mais efectiva que a tecnologia corrente e apresenta também menores custos. Nesta situação, diz-se que a tecnologia $T_{\text {o }}$ é dominada pela tecnologia $\mathrm{T}_{1}$, sendo a decisão óbvia, naturalmente, recaindo sobre $\mathrm{T}_{2}$, não havendo necessidade de cálculo do ICER. Convém referir que esta não é um cenário que ocorra com muita frequência. No cenário 3 a nova tecnologia $\mathrm{T}_{3}$, é menos efectiva do que a tecnologia corrente e apresenta também menores custos. Nesta situação, também não é óbvio que decisão tomar, e mais uma vez essa decisão depende do valor do ICER, e do julgamento do agente de decisão. Finalmente, é fácil verificar que para o cenário 4 a tecnologia corrente $\mathrm{T}_{0}$ domina a nova tecnologia $\mathrm{T}_{4}$, pois esta apresenta maiores custos e menor efectividade

A representação das tecnologias de saúde no plano $\mathrm{E} \times \mathrm{C}$, apesar de útil para explicar alguns conceitos, por exemplo o de dominância, não é efectuada com frequência nos estudos aplicados. Nestes, os programas de saúde são representadas no plano $\Delta \mathrm{E} \times \Delta \mathrm{C}$, painel da direita da Figura 4, o qual decorre directamente do painel apresentado no lado esquerdo, através da realização de uma translação do centro do sistema para o ponto $\mathrm{T}_{0}$. Neste novo referencial o eixo horizontal mede a efectividade incremental e o eixo vertical mede o custo incremental de $\mathrm{T}_{1}$ comparado com $\mathrm{T}_{0}$. Cada ponto neste novo referencial representa a nova tecnologia em termos comparativos, $\Delta \mathrm{E}=\mathrm{E}_{1}-\mathrm{E}_{0}$ e de $\Delta \mathrm{C}=\mathrm{C}_{1}-\mathrm{C}_{0}$. A tecno$\operatorname{logia} T_{i}$, representada no referencial do painel esquerdo da Figura, cairia no quadrante $i(\mathrm{i}=\mathrm{I}, \mathrm{II}, \mathrm{III}, \mathrm{IV})$ no referencial do painel da direita da Figura.

Para cada quadrante do referencial $\Delta \mathrm{E} \times \Delta \mathrm{C}$ a escolha entre $\mathrm{T} 0 \mathrm{e} \mathrm{T} 1$ seria a seguinte:

\begin{tabular}{|c|c|}
\hline Quadrante $\rightarrow$ & Regra de decisão \\
\hline 1 & $\mathrm{~T}_{1}>\mathrm{T}_{0}$ se e apenas se $\frac{\Delta \mathrm{C}}{\Delta \mathrm{E}}<\lambda$ \\
\hline ॥ & $\mathrm{T}_{1}>\mathrm{T}_{0}$ \\
\hline III & $\mathrm{T}_{1}>\mathrm{T}_{0}$ se e apenas se $\frac{\Delta \mathrm{C}}{\Delta \mathrm{E}}>\lambda$ \\
\hline IV & $\mathrm{T}_{0}>\mathrm{T}_{1}$ \\
\hline
\end{tabular}

em que $\lambda$ (limiar critico) representa o valor máximo que o agente de decisão está disposto a pagar por unidade adicional de efeito, representado pelo declive da recta a tracejado representada na Figura. Equivalentemente, $\lambda$ pode ser interpretado como o valor mínimo que a sociedade está disposta a aceitar por cada unidade de 


\begin{tabular}{|c|c|c|c|}
\hline \multicolumn{4}{|c|}{$\begin{array}{l}\text { QUADRO V. Exemplo de aplicação para utilização } \\
\text { do ICER }\end{array}$} \\
\hline Tecnologia & Custo Total & $\begin{array}{c}\text { Resultado } \\
\text { (QALY) }\end{array}$ & Rácio \\
\hline TO & $320.188 €$ & 142 & $2.255 €$ \\
\hline T1 & $670.555 €$ & 200 & $3.353 €$ \\
\hline $\begin{array}{l}\text { T1 em relação } \\
\text { a T0 }\end{array}$ & $350.367 €$ & 58 & $6.041 €$ \\
\hline
\end{tabular}

efeito de que está a abdicar. ${ }^{45}$ Designemos $\lambda$ como limiar de custo-efectividade (limiar CE)

Notar que estes rácios têm uma interpretação geométrica. $\mathrm{O}$ rácio incremental custo efectividade de $\mathrm{T}_{1}$ em relação a $T_{0}$ é dado pelo declive da recta que liga a origem do plano $\Delta \mathrm{E}$ - $\Delta \mathrm{C}$ ao ponto $\mathrm{T}_{1}$. Assim, no primeiro e terceiro quadrantes, todas as tecnologias localizadas abaixo da linha a tracejado - recta de declive $\lambda$ - são preferidas à prática clínica corrente.

Um exemplo ajuda a ilustrar os conceitos expostos até este ponto. Considere-se que existem dois programas de saúde em avaliação, $\mathrm{T}_{0}$ e $\mathrm{T}_{1}$, tendo de se optar pela implementação de um deles. Os seus custos totais e consequências, medidas em QALYs, são os apresentados no Quadro V. Admita-se que $\mathrm{T}_{0}$ é a prática clínica corrente. $\mathrm{T}_{0}$ apresenta um custo total de $320.188 €$ e ganhos de 142 QALYs, relativamente à opção de nada fazer. O programa $\mathrm{T}_{1}$ tem um custo total de $670.555 € \mathrm{e}$ ganhos em saúde de 200 QALYs, relativamente a nada fazer.

Este exemplo revela a situação mais comum em que o novo programa de saúde permite a obtenção de ganhos em saúde para a população, contudo também apresenta um custo mais elevado. $\mathrm{T}_{1}$, em relação a $\mathrm{T}_{0}$, permite a obtenção de 58 QALYs adicionais, porém também incrementa os custos em 350.367€. Cada um destes QALY adicional obtido por T1 custa $6.041 €=350,367 \div 58$, o valor do ICER. A escolha de $\mathrm{T}_{1}$ depende do limiar do valor que o agente de decisão está disposto a pagar por QALY ganho. Se esta disposição para pagar for superior a 6.041€ então $\mathrm{T}_{1}$ deve ser adoptada, caso contrário, dever-se-á manter a prática clínica corrente. A Figura 5 ilustra este exemplo do pronto de vista gráfico.

O exemplo serve ainda para mostrar a diferença entre custos médios e custos incrementais. Suponha-se

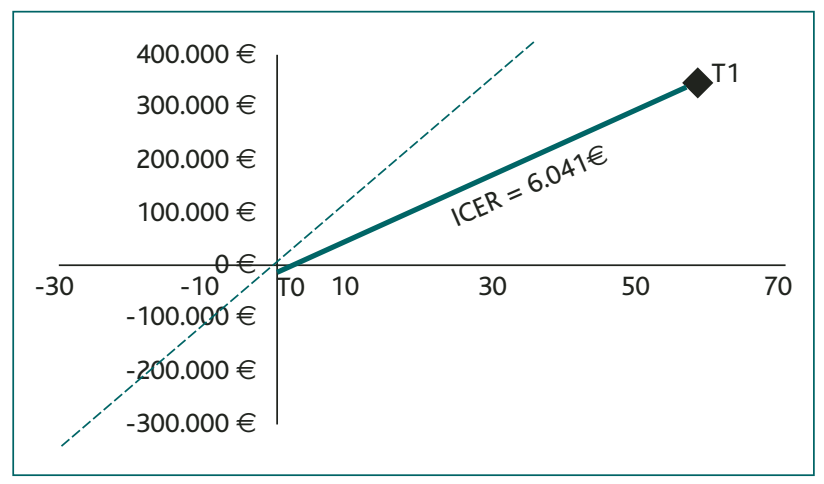

Figura 5. Exemplo de aplicação de utilização do ICER; Ilustração gráfica.

que não existe prática clínica corrente, e que T0 e T1 são duas novas tecnologias de saúde propostas para fazer face a um problema de saúde. Assim, a escolha de $\mathrm{T}_{0} \mathrm{im}$ plica que cada QALY ganho tem um custo médio de $2.255 €$. Por outro lado, a escolha de $\mathrm{T}_{1}$ tem um custo médio de $3.353 €$. A questão que agora se pode colocar é que tecnologia alternativa escolher, $\mathrm{T}_{0}$ ou $\mathrm{T}_{1}$ ? Essa resposta não se encontra na análise dos custos médios por QALY ganhos em cada tecnologia, mas sim na análise da relação do custo incremental de $\mathrm{T}_{1}$ em relação a $\mathrm{T}_{0} \mathrm{e}$ dos resultados incrementais, ainda de $\mathrm{T}_{1}$ em relação a $\mathrm{T}_{0}$, ou seja, na análise do ICER.

Focámos até agora toda a análise às situações em que existem apenas duas tecnologias em avaliação; contudo esta metodologia de cálculo e análise dos rácios custo-efectividade pode ser estendida ao estudo de casos em que existem diversas tecnologias de saúde em avaliação, sem dificuldades adicionais

Toda a análise conceptual apresentada ao longo desta secção assenta explicitamente na hipótese de que tanto os custos como os resultados das tecnologias de saúde em avaliação são determinísticos, portanto estimados sem incerteza e não sujeitos a variação aleatória. Concomitantemente, os rácios incrementais custo-efectividade são também assumidos determinísticos, e não sujeitos a variação aleatória e sem incerteza na sua estimação. Com vimos na secção anterior, esta hipótese de certeza no valor dos ICER deve ser questionada dada a potencial imprecisão que rodeia todas as questões metodológicas associadas à condução de um estudo de avaliação económica (especificação do modelo de decisão, identificação e medição de custos e de 
consequências, insuficiência dos dados disponíveis, etc.). Assim, é muito importante que as avaliações económicas de programas de saúde tratem explicitamente todos os elementos de incerteza na análise dos ICERs. Os métodos para o fazer foram tratados noutra parte deste texto.

Como vimos até este ponto, a decisão final acerca da tecnologia de saúde a adoptar depende criticamente da relação entre o rácio incremental custo-efectividade (ICER) e o limiar máximo da disposição para pagar por cada QALY ganho. Assim, para que o agente de decisão efectue a sua escolha de modo transparente é essencial conhecer o valor deste limiar. Apesar de terem sido propostos alguns métodos para a sua determinação, a estimação e explicitação do limiar CE não é comum na tomada de decisão pelas agências públicas. Sorenson, Drummond e Kanavos ${ }^{46}$ referem que poucos países têm um limiar formal ou fixo, ou pelo menos, se o usam, não o explicitam. Contudo, os agentes públicos tomam, de facto, decisões relativas à adopção de tecnologias, pelo que se pode concluir pela existência um valor implícito para este limiar CE. A este propósito vale a pena referir a controvérsia suscitada por decisões do NICE em não aconselhar o financiamento de alguns medicamentos no âmbito do SNS britânico. ${ }^{47} \mathrm{~A}$ agência afirma que não tem um valor orientador na tomada de decisão e que a aceitação ou rejeição de tecnologias de saúde depende de outros factores - contudo, o valor do ICER desempenha um papel fundamental nas decisões. ${ }^{47} \mathrm{Nes}-$ ta disputa está patente um conflito entre o valor que o NICE estabelece como limiar máximo para financiamento e o valor atribuído pelos doentes e seus familiares a esse mesmo limiar crítico, havendo naturalmente um grande desfasamento. Isto ilustra a dificuldade de estabelecer um limiar consensualmente aceite por todos os envolvidos e afectados pela decisão.

Alguns investigadores referem que em Inglaterra o limiar crítico implícito varia entre $£ 20000$ e $£ 30000$ por QALY, ${ }^{48}$ enquanto nos Estados Unidos este limiar varia entre os $\$ 20.000$ e $\$ 100.00$ por QALY ganho.

\section{CONCLUSÃO}

A avaliação económica é uma importante parte da ATS. Não sendo um comprimido milagroso capaz de resolver todas as dificuldades existentes, os estudos de avaliação económica são uma forma de estruturar e ana- lisar criticamente a informação sobre custos e consequências dos bens ou serviços em análise, para deste modo servir de base ao processo de decisão.

Existem várias ferramentas que podem ser utilizadas pelos estudos de avaliação económica, algumas das quais destinadas a resolver problemas relacionados com a incerteza, falta de disponibilidade de dados ou informação específica sobre o serviço em estudo.

No entanto, e apesar de todas as dificuldades subjacentes à aplicação ao sector da Saúde das metodologias da teoria Económica, a realização de estudos de avaliação económica é sempre uma excelente oportunidade para se conhecerem melhor os serviços de Saúde e permitir uma escolha mais informada entre utilizações alternativas dos sempre escassos recursos disponíveis.

\section{REFERÊNCIAS BIBLIOGRÁFICAS}

1. Drummond MF, Sculpher MJ, Torrance GW, O'Brien BJ, Stoddart G. Methods for the Economic Evaluation of Health Care Programmes. New York: Oxford University Press; 2005.

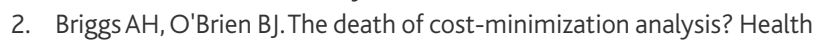
Econ 2001 Mar; 10 (2): 179-84.

3. Freemantle $\mathrm{N}$, Maynard A. Something rotten in the state of clinical and economic evaluations. Health Econ 1994 Mar-Apr; 3 (2): 63-7.

4. Zweifel P, Breyer F. Health economics. New York: Oxford University Press; 1997.

5. Torrance GW. Measurement of health state utilities for economic appraisal. J Health Econ 1986 Mar; 5 (1): 1-30.

6. Dolan P. The measurement of health-related quality of life for use in resource allocation decisions in health care. In: Culyer AJ, Newhouse JP, editors. Handbook of Health Economics. Amsterdam: Elsevier; 2000. p. 1723-60.

7. Brazier J, Roberts J, Deverill M. The estimation of a preference-based measure of health from the SF-36. J Health Econ 2002 Mar; 21 (2): 271$-92$.

8. Brazier J. Measuring and valuing health benefits for economic evaluation. New York: Oxford University Press; 2007.

9. Ferreira P, Ferreira L. Medição de preferências em saúde na população portuguesa. Rev Port Saúde Pública 2006; 24 (2): 5-14.

10. Ribeiro PJ. O importante é a saúde: estudo de adaptação de uma técnica de avaliação do estado de saúde - SF-36. Lisboa: Fundação Merck Sharp \& Dohme; 2005.

11. Ferreira L. Utilidades, QALYs e medição da qualidade de vida. Rev Port Saúde Pública. 2003; Vol. Temát. 3: 51-63.

12. Williams A. EuroQol: a new facility for the measurement of health-related quality-of-life. Health Policy. 1990 Dec; 16 (3): 199-208.

13. Kaplan RM,Anderson JP.A general health-policy model: update and applications. Health Serv Res 1988 Jun; 23 (2): 203-35.

14. Dolan P, Gudex C, Kind P, Williams A. The time trade-off method: results from a general population study. Health Econ 1996 Mar-Apr; 5 (2): 141-54. 
15. Dolan P, Gudex C, Kind P, Williams A. A social tariff for EuroQol: results from a UK general population survey. York: The University of York, Center for Health Economics; 1995.

16. Williams A. Economics, Qalys and Medical-Ethics - a Health Economists Perspective. Health Care Anal 1995 Aug; 3 (3): 221-6.

17. Knapp M, Mangalore R. "The trouble with QALYs ..." Epidemiol Psichiatr Soc 2007 Oct-Dec; 16 (4): 289-93.

18. McGregor M, Caro JJ. QALYs. are they helpful to decision makers? Pharmacoeconomics 2006; 24 (10): 947-52.

19. Vijan S. Should we abandon QALYs as a resource allocation tool? Pharmacoeconomics 2006; 24 (10): 953-4.

20. Bleichrodt H, Pinto JL. The validity of QALYs under non-expected utility. Econ J 2005 Apr; 115 (503): 533-50.

21. Mehrez A, Gafni A. Healthy-years equivalents versus quality-adjusted life years - in pursuit of progress. Med Decis Making 1993 Oct-Dec; 13 (4): 287-92.

22. Gafni A, Birch S, Mehrez A. Economics, health and health economics: HYEs (healthy-years equivalents) versus QALYs (quality-adjusted liveyear). J Health Econ 1993 Oct; 12 (3): 325-39.

23. Mehrez A, Gafni A. The healthy-years equivalents: how to measure them using the standard gamble approach. Med Decis Making 1991 Apr-Jun; 11 (2): 140-6.

24. Mehrez A, Gafni A. Quality-adjusted life years, utility theory, and healthy-years equivalents. Med Decis Making 1989 Apr-Jun; 9 (2): 142 $-9$.

25. Nord E. An alternative to QALYs: the Saved Young Life Equivalent (SAVE). BMJ 1992 Oct 10; 305 (6858): 875-7.

26. Mullahy J. Live long, live well: quantifying the health of heterogeneous populations. Health Econ 2001 Jul; 10 (5): 429-40.

27. McKenna MT, Michaud CM, Murray CJ, Marks JS. Assessing the burden of disease in the United States using disability-adjusted life years. Am J Prev Med 2005 Jun; 28 (5): 415-23.

28. Murray CJ, Lopez AD. Global mortality, disability, and the contribution of risk factors: Global Burden of Disease Study. Lancet 1997 May 17; 349 (9063): 1436-42.

29. Murray CJ. Quantifying the burden of disease: the technical basis for disability-adjusted life years. Bull World Health Organ 1994; 72 (3): 429-45 .

30. Buxton MJ, Drummond MF, Van Hout BA, Prince RL, Sheldon TA, Szucs T, et al. Modelling in economic evaluation: an unavoidable fact of life. Health Econ 1997 May-Jun; 6 (3): 217-27.

31. Briggs $A H$. Handling uncertainty in economic evaluation and presenting the results. In: Drummond MF, McGuire A, editors. Economic evaluation in health care: merging theory with practice. Oxford, Oxford University Press; 2001. p. 172-214.

32. Sun $X$, Faunce T. Decision-analytical modelling in health-care economic evaluations. Eur J Health Econ 2008 Nov; 9 (4): 313-23.

33. Briggs AH, Claxton K, Sculpher MJ. Decision modelling for health economic evaluation. New York: Oxford University Press; 2006.

34. Drummond MF, McGuire A. Economic evaluation in health care: merging theory with practice. New York: Oxford University Press; 2001.

35. Brennan A, Chick SE, Davies R. A taxonomy of model structures for economic evaluation of health technologies. Health Econ 2006 Dec; 15 (12): 1295-310.
36. Félix J, Inês M, Acosta C. Análise probabilistica de custo-efectividade: utilização do eletriptano no tratamento das crises de enxaqueca em Portugal. Acta Méd Port 2005 Jan-Fev; 18 (1): 77-87.

37. Karnon J.Alternative decision modelling techniques for the evaluation of health care technologies: Markov processes versus discrete event simulation. Health Econ 2003 Oct; 12 (10): 837-48.

38. INFARMED. Orientações metodológicas para estudos de avaliação económica de medicamentos. INFARMED: Portugal; 1998.

39. Briggs A, Sculpher M, Buxton M. Uncertainty in the economic-evaluation of health-care technologies: the role of sensitivity analysis. Health Econ 1994 Mar-Apr; 3 (2): 95-104.

40. Gold MR, Siegel JE, Russell LB, Weinstein MC. Cost-effectiveness in health and medicine: New York: Oxford University Press; 1996.

41. Grieve AP. Issues for statisticians in pharmaco-economic evaluations. Stat Med 1998 Aug 15-30; 17 (15-16): 1715-23.

42. Philips Z, Bojke L, Sculpher M, Claxton K, Golder S. Good practice guidelines for decision-analytic modelling in health technology assessment: a review and consolidation of quality assessment. Pharmacoeconomics 2006; 24 (4): 355-71.

43. Philips Z, Ginnelly L, Sculpher M, Claxton K, Golder S, Riemsma R, et al. Review of guidelines for good practice in decision-analytic modelling in health technology assessment. Health Technol Assess 2004 Sep; 8 (36):1-158.

44. Consensus Conference on Guidelines on Economic Modelling in Health Technology Assessment. Decision analytic modelling in the economic evaluation of health technologies: a consensus statement. Pharmacoeconomics 2000 May; 17 (5): 443-4.

45. Stinnett AA, Mullahy J. Net health benefits: a new framework for the analysis of uncertainty in cost-effectiveness analysis. Med Decis Making 1998 Apr-Jun; 18 (2 Suppl): S68-S80.

46. Sorenson C, Drummond M, Kanavos P. Ensuring value for money in health care: the role of health technology assessment in the European Union. Copenhagen: European Observatory on Health Systems and Policies; 2008.

47. Appleby J, Devlin N, Parkin D. NICE's cost effectiveness threshold: how high should it be? BMJ 2007 Aug 25; 335 (7616): 358-9.

48. Devlin N, Parkin D. Does NICE have a cost-effectiveness threshold and what other factors influence its decisions? A binary choice analysis. Health Econ 2004 May; 13 (5): 437-52.

\section{ENDEREÇO PARA CORRESPONDÊNCIA}

Óscar Lourenço

Faculdade de Economia da Universidade de Coimbra

Av. Dias da Silva, 165

3004-512 Coimbra

E-mail: osl@fe.uc.pt 


\section{ABSTRACT}

This article offers a general perspective on the main methods used on the economic evaluation of health technologies and it describes how these methods help to base the decisions concerning their use on credible scientific evidences obtained through systematic and transparent means.

The scientific literature identifies four types of economic evaluation of health programs: cost analysis, cost-effectiveness analysis, cost-utility analysis and cost-benefit analysis.

The cost-effectiveness analysis (which measures the consequences on natural units) and cost-utility analysis (which measures the consequences on QALYs: Quality-Adjusted Life Years) are the most frequently analysis used on processes of Evaluation of Health Technologies.

When there are no available economic or effectiveness data on an individual level derived from quality clinical essays eligible for use on economic evaluation studies, it is necessary to resort to mathematic models that combine and synthesize all the available evidence. Scientific modelling also permits to extrapolate from intermediate consequences to final consequences or to an adequate time horizon, to incorporate elements of uncertainty and also to extrapolate consequences of the health programs (effectiveness/QALYs) to the real context in which they will be applied.

The unavoidable uncertainty associated with every type of economic evaluation must be measured and integrated in the analysis; there are techniques that allow to carry out this goal, providing the politic decision-maker with an assessment of the strength of the economic evaluation conclusions.

The most common indicator used to confront costs and consequences in economic evaluation studies is the Incremental Cost-Effectiveness Ratio (ICER). Its estimate and application in the elaboration of the final recommendations of economic evaluation studies will be described on the last chapter of this article. 